\title{
Object grasping and manipulation in capuchin monkeys (genera Cebus and Sapajus)
}

\author{
VALENTINA TRUPPA ${ }^{1 *,}$, PAOLA CARDUCCI ${ }^{1,2}$ and GLORIA SABBATINI ${ }^{1}$ \\ ${ }^{1}$ Institute of Cognitive Sciences and Technologies, National Research Council (CNR), Via Ulisse \\ Aldrovandi 16/b, 00197, Rome, Italy \\ ${ }^{2}$ Environmental and Evolutionary Biology PhD Program, Department of Environmental Biology, \\ Sapienza University of Rome, Piazzale Aldo Moro 5, 00185, Rome, Italy
}

Received 14 June 2018; revised 20 July 2018; accepted for publication 12 August 2018

\begin{abstract}
The abilities to perform skilled hand movements and to manipulate objects dexterously are landmarks in the evolution of primates. The study of how primates use their hands to grasp and manipulate objects in accordance with their needs sheds light on how these species are physically and mentally equipped to deal with the problems they encounter in their daily life. We report data on capuchin monkeys, highly manipulative platyrrhine species that usually spend a great deal of time in active manipulation to search for food and to prepare it for ingestion. Our aim is to provide an overview of current knowledge on the ability of capuchins to grasp and manipulate objects, with a special focus on how these species express their cognitive potential through manual behaviour. Data on the ability of capuchins to move their hands and on the neural correlates sustaining their actions are reported, as are findings on the manipulative ability of capuchins to anticipate future actions and to relate objects to other objects and substrates. The manual behaviour of capuchins is considered in different domains, such as motor planning, extractive foraging and tool use, in both captive and natural settings. Anatomofunctional and behavioural similarities to and differences from other haplorrhine species regarding manual dexterity are also discussed.
\end{abstract}

ADDITIONAL KEYWORDS: bimanual coordination - exploration - extractive foraging - manual dexterity motor planning - power grip - precision grip - thumb opposability - tool use.

\section{INTRODUCTION}

Primates use their hands to exploit a wide range of resources in their environment. The abilities to perform skilled hand movements and to manipulate objects are landmarks in the evolution of these species. Object grasping and manipulation vary across primate clades in relationship to (1) anatomofunctional constraints regulating the movement of all the anatomical segments of their thoracic limb and to (2) cognitive skills, such as their ability to plan actions and to relate objects to other objects and substrates. Therefore, the study of how primates use their hands to grasp and manipulate objects in accordance with their needs reveals how these species are physically and mentally equipped to deal with many crucial problems they encounter in their environment. The connection between cognitive

*Corresponding author. E-mail: valentina.truppa@istc.cnr.it mechanisms and motor behaviours can be understood better by considering actions as inextricably grounded in ongoing engagement with the environment and knowledge as inseparable from practice.

Among haplorrhines, highly manipulative skills are more common in catarrhines than in platyrrhines, except for capuchin monkeys. Capuchins are medium-sized New World monkeys that usually spend a great deal of time in active manipulation to search for food and to prepare it for ingestion (Fragaszy et al., 2004b). Capuchins species were formerly identified as the single genus Cebus, whereas currently they are classified in two distinct genera, with the robust (tufted) forms now recognized as the genus Sapajus and the gracile (untufted) forms retained as the genus Cebus (Lynch Alfaro et al., 2012). In this paper, we report findings on grasping and manipulation in capuchins by referring to species names, when available, in accordance with their current taxonomy.

Ever since capuchin monkeys have attracted the attention of scientists, they have been well known for 
their manual dexterity and propensity to manipulate objects, including their ability to use objects as tools (Romanes, 1883). Interest in their manual ability has expanded in the last few decades, including studies in both natural and captive settings (Fragaszy et al., 2004b). Despite the fact that platyrrhines started their independent evolution from catarrhines $~ 30-40$ Mya (Schrago \& Russo, 2003), capuchins show several important parallelisms with species such as chimpanzees and humans, including a prolonged infancy and juvenile period, a long lifespan, advanced cognitive skills and complex manipulative abilities. Therefore, capuchins have become a particularly interesting model for testing hypotheses regarding the evolution of primate cognition and manual dexterity.

Our aim is to provide a brief critical overview of current knowledge on the ability of capuchins to grasp and manipulate objects, with special focus on how these species express their cognitive potential through manual behaviour. Grasping behaviour and object manipulation rely on both motor and cognitive skills. Although movements fundamentally depend on generating, controlling and exploiting physical forces, managing forces requires more than muscles and biomechanics. In fact, motor behaviour requires cognitive ability in selecting actions and acknowledging errors in addition to motor ability in executing actions. More generally, motor actions bring about new opportunities for generating perceptual information and providing the means for acquiring knowledge about the world, and expanding motor skills can prompt cascades of changes in perceptual, cognitive and social domains (Adolph \& Franchak, 2017). In this view, motor behaviours cannot be understood in isolation, separated from the bodily and environmental context in which they occur. Thus, perception and action are considered to be interrelated, and cognition is embodied and grounded in the sensorimotor system (Gibson, 1986; Cisek \& Kalaska, 2010). We will adopt an actionperception framework to describe the studies on object grasping and manipulation in capuchin monkeys and to discuss how they contribute to our knowledge about the connection between cognition and action. In the following sections, first we report data on the ability of capuchins to move their hands and then we consider findings on the manipulative behaviour of capuchins in relationship to their cognitive abilities in different domains, such as action planning, extractive foraging and tool use.

\section{OBJECT GRASPING AND MANUAL DEXTERITY}

\section{ANATOMOFUNCTIONAL CORRELATES}

Capuchin monkeys have very dexterous and versatile hands. The flexible use of the hand in capuchins is supported by several anatomofunctional features, which in some respects parallel those of catarrhines.

The brain size and cross-sectional spinal cord area of capuchins are larger than expected for primates of their body mass (Rilling \& Insel, 1999). It has been supposed that the enlarged brain and spinal cord area convey an augmented number of sensorimotor fibres to support the manual dexterity and manipulative skills of capuchins (Rilling \& Insel, 1999). At the cortical level, capuchins have the following characteristics: (1) well-differentiated somatosensory maps of the hands, particularly for the glabrous skin of palms and digits (Carlson \& Nystrom, 1994); (2) multiple premotor areas in the frontal lobe (Dum \& Strick, 2005); and (3) well-differentiated parietal area 2, associated with proprioception, and area 5, associated with motor planning and internal body coordinates for visually guided reaching, grasping and manipulation (Padberg et al., 2007). Interestingly, both the location and the organization of parietal areas 2 and 5 more closely resemble those of macaques (Pons et al., 1985), i.e. Old World monkeys known for their manual dexterity (e.g. Macfarlane \& Graziano, 2009), than the poorly developed or absent parietal areas 2 and 5, of less dexterous species of New World monkeys, such as squirrel monkeys, titi monkeys, marmosets and owl monkeys (Merzenich et al., 1978; Sur et al., 1982; Coq et al., 2004; Padberg et al., 2005, 2007). These findings indicate that some parietal areas associated with sophisticated hand use emerged independently in some primates and raise the question of how this parallel organization evolved. Moreover, in capuchins, the primary motor cortex (M1) neurons, which send cortical projections to the ventral premotor cortex, dorsal premotor cortex, supplementary motor area and parietal area 5, are concentrated in specific zones within the M1 hand area that are largely segregated from one another (Hamadjida et al., 2016). It has been proposed that this detailed modular organization within the M1 hand area could sustain parallel processing of interactions with multiple specialized cortical areas to increase the complexity of hand movements (Hamadjida et al., 2016). In addition, more peripherally, the manual dexterity of capuchins is supported by a dense substrate of direct corticospinal terminations at the ventral horn of cervical segments of the spine, from where motoneurons originate to innervate the hand muscles; this substrate is consistently denser than that of squirrel monkeys (Bortoff \& Strick, 1993).

Capuchin monkeys, like other primate species, possess convergent-divergent digits. Convergence and divergence movements are crucial for prehensile behaviour. Convergent movement occurs at the metacarpophalangeal joints and consists of flexion and adduction, leading to the juxtaposition of the 
fingertips (Napier \& Napier, 1967). Conversely, divergence is a movement of extension and abduction that leads to a fanning of the digits (Napier \& Napier, 1967). Capuchins have a relatively deep carpal arch, which enhances the approximation of the tips of the digits in convergence and their spread in divergence (Napier \& Napier, 1967). This arrangement of carpal bones is also supposed to improve opposability and the strength of the digital flexors (Napier, 1960, 1961). For the grasping and manipulation of objects, the degree of divergence and opposability of the thumb is particularly important. The thumb of capuchins is almost exactly lined up in series with the other fingers, and it can be abducted at least $45^{\circ}$ from the forefinger (Hill, 1960; Napier \& Napier, 1967). Among other characteristics, the carpometacarpal joint of the thumb deserves particular attention because it determines the relative independence of movement from the rest of the digits. Capuchins have a modified hinge-shaped trapezium-metacarpal joint (Napier \& Napier, 1967), which has an arrangement that resembles morphologically the saddle-type joint typical of catarrhines; it is concave at the base of metacarpal I and convex at the articular face of the trapezium, yielding a $90^{\circ}$ angle between them (Ankel-Simons, 2007; Aversi-Ferreira et al., 2014). Nevertheless, this articulation in capuchins is considered to be of the hinge variety (Napier $\&$ Napier, 1967). Indeed, in functional terms, it allows flexion-extension and abduction-adduction by means of angular displacements, whereas rotational movements are absent or very limited (Napier \& Napier, 1967; Aversi-Ferreira et al., 2014). Given that the rotation of metacarpal I over the trapezium is essential to achieve the pad-to-pad opposition between the distal phalanx of the thumb and those of the other fingers, capuchins do not have a fully opposable thumb (Napier, 1961; Napier \& Napier, 1967). Capuchins can oppose the lateral aspect of the thumb with the lateral aspects of other fingers or palm; this form of opposability has been classified as 'pseudo-opposability' (Napier \& Napier, 1967) and, more recently, it has also been defined as 'lateral opposability' (Christel \& Fragaszy, 2000). In comparison to Old World primates and squirrel monkeys, the thumbs of capuchins are proportionally longer relative to the other digits (Napier \& Napier, 1967; Fragaszy et al., 1989). It has been suggested that the relatively long thumb of capuchins affords a biomechanical advantage in achieving precision grips by lateral opposition (Fragaszy et al., 1989).

Alongside peculiar skeletal structures, capuchins also have muscular characteristics that enhance the movements of the thumb and set them apart from other platyrrhines. Namely, in capuchins: (1) the extensor pollicis longus inserts in digit 1 only, and it is not completely blended with extensor indicis; and (2) the anterior part of the abductor pollicis longus is separated into two tendons. This myological arrangement allows not only movements of the thumb independent from the other hand structures but also the ability to exert strong thumb manipulative forces (AversiFerreira et al., 2010, 2011). These findings confirm the evolutionary convergence of hand and forearm anatomy between capuchins and catarrhines, particularly chimpanzees and humans.

The manipulative skills of capuchins are also based on their ability to process tactile input from the hand. The capuchin hand has well-developed volar tactile pads (Hill, 1960: 327). Histological analyses have revealed that the dermal papillae of their volar skin show clearly visible Meissner corpuscles (MCs; Lemelin, 2000). Meissner corpuscles are somatosensory mechanoreceptors mostly located in the cutaneous pads of the hands and feet of primates and marsupials but absent in most eutherian taxa (Winkelmann, 1963; Hoffmann et al., 2004). It has been hypothesized that MCs provide an enhanced tactile sensitivity and that they could have played an important role in the evolution of locomotion in the fine-branch niche of arboreal environments (Martin, 1990) and in the evolution of manipulative abilities (Hoffmann et al., 2004). Moreover, owing to the positive correlation between the density of MCs and frugivory, MCs are thought to be crucial for a rapid assessment of fruit texture and edibility (Hoffmann et al., 2004). Although scarce, findings on the density of MCs in capuchins (Sapajus apella) indicate that high tactile acuity sets these monkeys apart from other platyrrhines and that their tactile acuity is comparable to that of catarrhine species such as macaques (Macaca mulatta), thus suggesting again an independent evolution of similar neural organization in these distantly related primate species (Lemelin, 2000).

\section{ONTOGENY}

Owing to the crucial role of hands in the behavioural repertoire and lifestyle of capuchins, the ontogeny of their manipulative abilities has greatly interested researchers over the years. Most of the studies have been conducted in capuchins in captivity (e.g. Spinozzi, 1989; Fragaszy, 1990; Adams-Curtis \& Fragaszy, 1994; Byrne \& Suomi, 1995; Fragaszy \& Adam-Curtis, 1997), but more recently, the development of dexterous foraging activities has also been studied in wild conditions (e.g. Gunst, et al., 2008, 2010a, b; Fragaszy et al., 2017).

Interestingly, the developmental patterns of capuchin monkeys differ from those observed in squirrel monkeys and Old World monkeys, such as macaques, and are more similar to those observed in humans and apes (Spinozzi, 1989; Fragaszy, 1990; Fragaszy et al., 
1991; Adams-Curtis \& Fragaszy, 1994). In particular, compared with squirrel monkeys (Saimiri spp.), in the first few months after birth capuchins exhibit a greater degree of motoric altriciality and reach independent locomotion and activities, such as foraging, less precociously (Fragaszy et al., 1991; Stone, 2006). Like humans and apes, capuchins start to manipulate objects before showing independent locomotion. However, although manipulation appears before quadrupedal locomotion, dexterous prehension is not observed in capuchins for a long period after birth (Elias, 1977; Spinozzi, 1989; Fragaszy, 1990). From birth, newborn infant capuchins are able to perform a 'double lock' grip (Napier, 1993), used to cling to the mother (Fragaszy et al., 2004b). In this secure grip, the terminal phalanges curl and oppose the middle and first phalanges, allowing the support of the full weight of the body.

Adams-Curtis \& Fragaszy (1994) described the development of manipulation in captive capuchins during the first 6 months of life. The authors delineated three periods in terms of manual actions performed by infant capuchins within this time span. Initial attempts to grasp were observed in the first 8 weeks of life, but they did not cause object grasping and retrieval. In fact, although sustained visual orientation was possible during this period, precisely oriented or controlled manual actions were still absent. The second 8 week period showed an increase in manual activity and important changes in postural control and locomotion. During object reaching, the fingers appeared parallel rather than splayed. Capuchins mostly grasped and held objects or touched surfaces, but they also started to show their dexterous manipulative repertoire (e.g. pounding objects on substrates, rubbing and tapping). Finally, during the third 8 week period the repertoire of actions included all adult activities that require precisely controlled movements and actions of the digits (Adams-Curtis \& Fragaszy, 1994; Fragaszy et al., 2004b). Byrne \& Suomi (1995) investigated the development of explorative behaviour in captive capuchins from birth to 1 year of age. Infants began to leave mothers and explore environments from 3 to 8 weeks. Although not weaned until the end of the first year, by 7-9 months the infants spent more time alone or with other group members than with their mothers. According to these authors, environmental exploration began in the second month and reached stable levels by 4 months. In particular, complex manipulation of food and objects first began at 3-4 months and increased to stable levels in the second half of the first year (Byrne \& Suomi, 1995).

More recently, several studies conducted in the wild have shown how infant capuchins approach foraging activity and learn to process embedded or hidden foods efficiently (e.g. Gunst et al., 2008, 2010a, b; Fragaszy et al., 2017). All these studies demonstrated that immature animals are less efficient than adults in terms of foraging activities that require skill and strength. Nevertheless, immature individuals persistently forage without profit, attempting to harvest high-quality resources that are hard to obtain; this could facilitate their acquisition of suitable skills and effective foraging behaviours. In particular, several factors could be crucial for the differences reported in foraging efficiency, such as physical maturation, nutritional needs, independent foraging practice and the social context of foraging (Fedigan, 1990; Agostini \& Visalberghi, 2005; Gunst et al., 2008, 2010b; Resende et al., 2008; Fragaszy et al., 2017).

Overall, studying the ontogeny of manipulation in capuchin monkeys is of crucial importance to clarify how these species interact with the environment, detect affordances of each manipulative action and learn.

\section{GRIP PATTERNS AND THUMB USE}

Capuchin monkeys can perform a large variety of manual movements, ranging from extremely forceful to extremely delicate and precise actions (Fragaszy et al., 2004b). They use a variety of hand postures to grasp food and objects. In their different variants, the grips used by capuchins fall into one of two general classes defined by John Russell Napier $(1956,1993)$ as 'power' and 'precision' grips. According to Napier (1956), in power grips the object is held between the surface of the partly flexed fingers and the palm, with the thumb acting as the reinforcing agent, whereas in precision grips the object is pinched between the tips of the fingers and the opposed thumb. Detailed analysis of hand use by capuchins during grasping actions has been carried out almost exclusively in captive settings (e.g. Costello \& Fragaszy, 1988; Christel \& Fragaszy, 2000; Spinozzi et al., 2004; Pouydebat et al., 2009; Truppa et al., 2016). These studies revealed that they use several types of precision (Costello \& Fragaszy, 1988; Christel \& Fragaszy, 2000; Spinozzi et al., 2004; Pouydebat et al., 2009) and power grips (Spinozzi et al., 2004; Truppa et al., 2016). Owing to the anatomofunctional constraints described above, capuchins cannot achieve the classic tip-to-tip grip observed in humans and Old World nonhuman primates, such as macaques (Macfarlane \& Graziano, 2009). However, when required to grasp a small food item fixed to a tray with only one hand, capuchins showed a total of 16 precision grip variants and four power grip variants (Spinozzi et al., 2004). Precision grips mostly involved the distal lateral areas of the thumb and the index finger (Spinozzi et al., 2004; 
Fig. 1). Among other platyrrhines, the ability to use the side of the thumb against the side of the index finger has been described only in uakari monkeys (genus Cacajao), although this finding needs further observations to be confirmed (Bishop, 1964). In contrast, scissor grips, i.e. grips performed between digits 2 and 3 or digits 3 and 4 without the involvement of the thumb, have been observed in capuchins (Costello \& Fragaszy, 1988; Spinozzi et al., 2004) and in other platyrrhine taxa, such as Ateles, Lagothrix, Cacajao (Bishop, 1964) and Saguinus (Lemelin \& Grafton, 1998; for a recent review on manual functions in primates, see Fragaszy $\&$ Crast, 2016). Thus, the ability to oppose the thumb to the other fingers seems to set capuchins apart from other platyrrhine species.

In capuchins, the use of the thumb in opposition to the other areas of the hand also appears to be common in power grips for objects of different sizes (Spinozzi et al., 2004; Truppa et al., 2016). Spinozzi et al. (2004) found that the most preferred power-grip variant for small items involved the thumb and the palm, with the thumb being enclosed by the other fingers. Moreover, Truppa et al. (2016) found that, when grasping a vertical dowel, capuchins preferred to use a power-grip variant by abducting the thumb to wrap the object in the opposite direction with respect to the other fingers. In this manner, they pushed the object against both the palm and the other fingers. Overall, these findings indicate that capuchins have flexible use of the thumb during power grips; they are able to use the thumb in

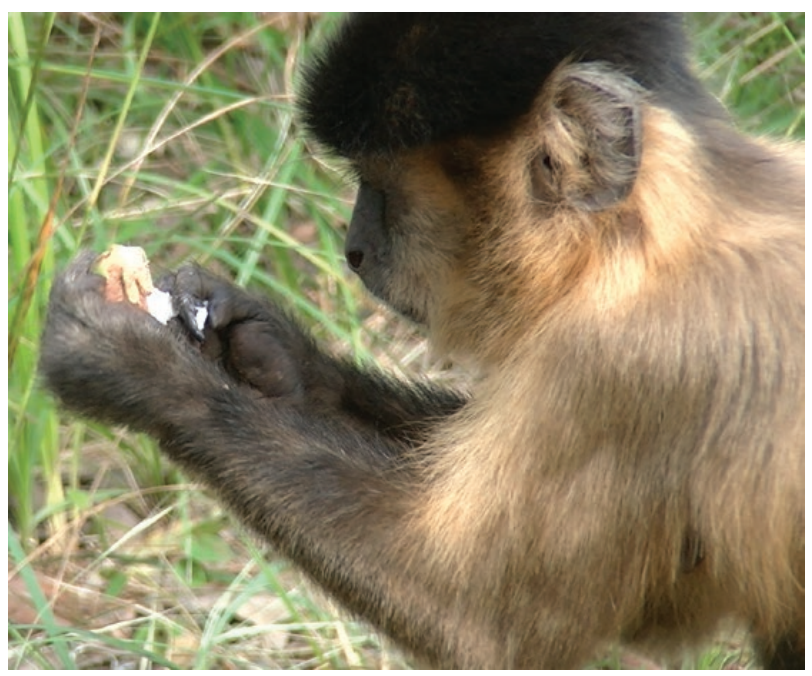

Figure 1. An adult female capuchin (Sapajus libidinosus) holds a broken palm nut with her left hand and uses a precision grip involving the distal lateral areas of the thumb and the index finger to grasp a small piece of nut kernel with her right hand. Photograph by V. Truppa, EthoCebus project. opposition, but they may also place it parallel to the other fingers (Fig. 2).

Given their variable use of the thumb, capuchins represent a very interesting taxon for future research on factors affecting the thumb posture in grasping actions. The ability to use the thumb in relationship to the other areas of the hand is a key feature of manual dexterity in primates. We suggest that the study of capuchins, whose features resemble partly those of platyrrhines and partly those of catarrhines, might help to clarify to what extent the degree of thumb mobility promotes object grasping and manipulation in primate species.

\section{MOTOR PLANNING FOR GRASPING OBJECTS}

Motor actions, such as reaching for and grasping objects, are often guided by the actor's anticipation of forthcoming postural and task demands. Studies on human and nonhuman primates have demonstrated that the rudimentary motor planning abilities appear to be shared across species (Rosenbaum et al., 2013). Interestingly, capuchins showed more pronounced motor planning abilities in tasks in which the principal axis of the graspable object was aligned with the horizontal plane (Zander \& Judge, 2015; Sabbatini et al., 2016) compared with the vertical plane (Zander et al., 2013; Truppa et al., 2016). In fact, when presented with a horizontal baited dowel containing food in its right or left end, capuchins switched the hands between trials to use a radial grip (with the thumbside oriented towards the baited end), with the forearm in pronation to bring the baited end easily to the mouth (Fig. 3; Zander \& Judge, 2015; Sabbatini et al., 2016). In contrast, when presented with either a baited cup with the opening facing down (Zander et al., 2013) or a dowel with its baited end inserted into a vertical tube (Truppa et al., 2016), capuchins did not use initial radial (thumb-down) grips more frequently than ulnar (thumb-up) grips to grasp the stem or dowel. In these cases, an initial radial grip would allow the stem or dowel to be rotated more easily and to reach a comfortable final hand posture, i.e. a final posture that allows good control of manual movements to be exerted. Moreover, capuchins showed action-selection planning when using tools to interact with distally located targets; they consistently used a radial grip (with the thumb-side oriented towards the centre of the dowel) to grasp a dowel that was positioned horizontally at different orientations and to dislodge an out-of-reach food reward (Sabbatini et al., 2016). The same finding has been demostrated in chimpanzees by Frey \& Povinelli (2012). Motor and precision requirements of tool use tasks probably induce capuchins and chimpanzees to perform a more pronounced degree of anticipatory planning. 

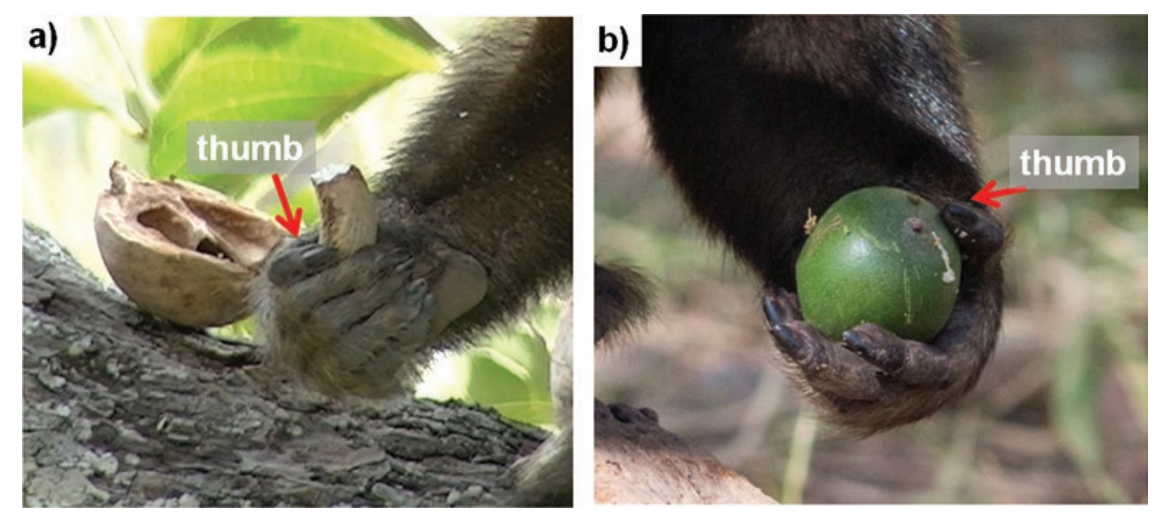

Figure 2. Capuchins can perform power grips with the thumb in parallel (A) or in opposition (B) to the other digits. Photographs by V. Truppa and L. A. Marino, EthoCebus project.
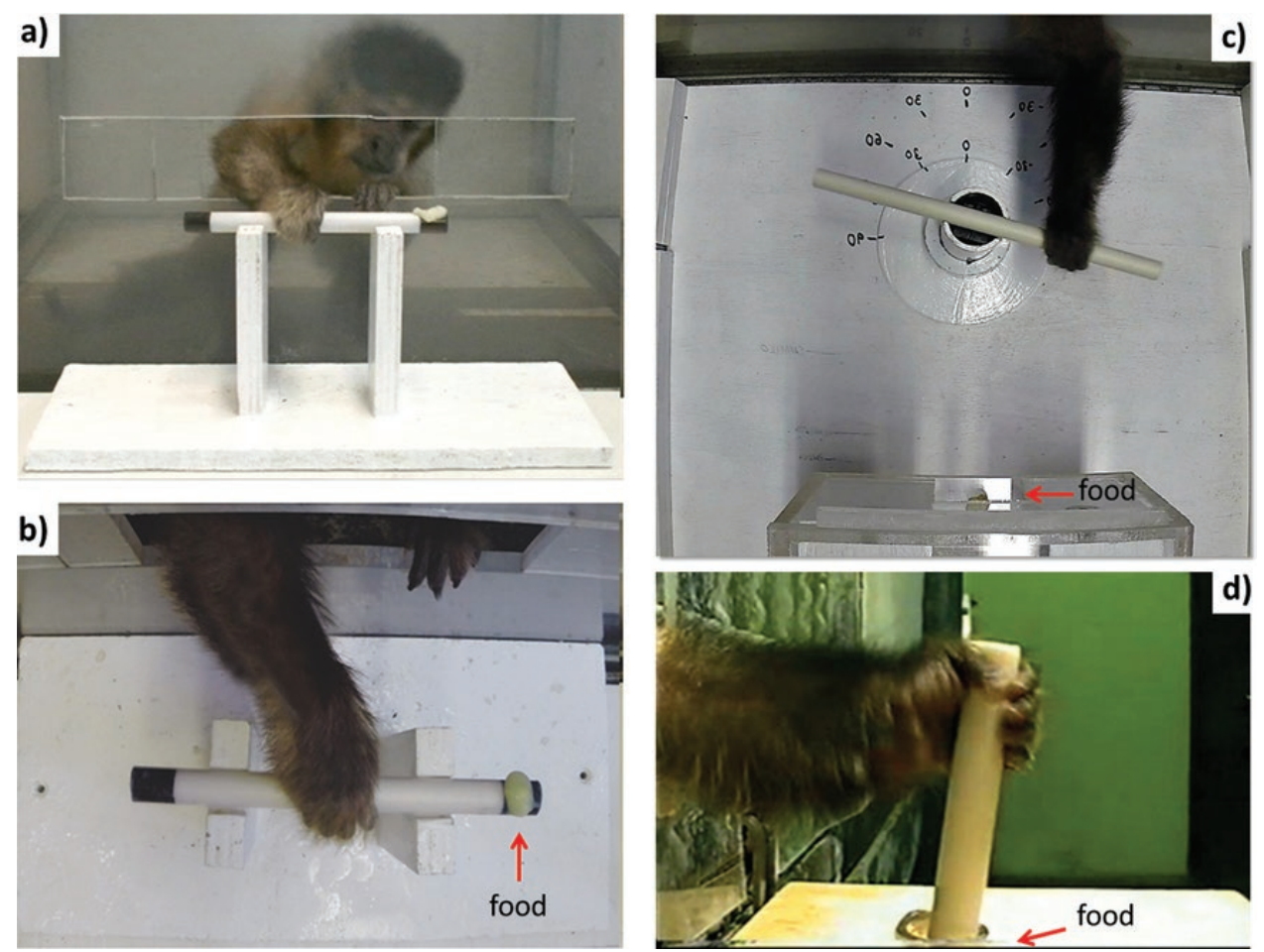

Figure 3. Capuchins could reach and grasp the object through a Plexiglass panel, as depicted in (A), in order to bring the baited end of a horizontal dowel to the mouth (B; Sabbatini et al., 2016), use a dowel positioned horizontally at different orientations to dislodge an out-of-reach food item (C; Sabbatini et al., 2016) and bring the baited end of a vertical dowel to the mouth (D; Truppa et al., 2016).

\section{NON-PREHENSILE MOVEMENTS}

Non-prehensile hand movements are those 'in which no grasping or seizing is involved, but by which objects can be manipulated by pushing or lifting motions of the hand as a whole or of the digits individually' (Napier, 1956: 902). Capuchins use non-prehensile skilled movements in different contexts, such as the following: (1) tapping, i.e. gently and repeatedly beating objects and surfaces, with finger nails to localize hidden food sources; (2) rolling food between their hands or against the tree bark; (3) digging in the ground to unearth underground plant parts or fossorial arthropods; and (4) probing into narrow holes or crevices using a single digit to extract food sources. The last of these, in particular, seems to set capuchins apart from other platyrrhines, because it requires 
the ability to move single digits independently. For example, Spinozzi et al. (2007) showed that capuchins are able to move single digits independently when the fingers are retrieving a small food item inside a narrow tube, and they display a high mobility of the distal phalanx joints. In the following sections, we will report several examples of these types of hand movements performed by capuchins while foraging.

\section{OBJECT EXPLORATION AND MANIPULATION}

\section{PERSISTENCE AND VARIETY}

Persistent and varied manipulation of objects and surfaces is a typical characteristic of capuchin monkeys (Fragaszy et al., 2004b). Their activity towards objects and substrates is predominated by actions in which they act directly with the body on a surface or an object (Fragaszy et al., 2004b). Moreover, capuchins, like chimpanzees (Pan troglodytes; Takeshita \& Walraven, 1996), also frequently combine objects and surfaces in actions (e.g. they bang objects on surfaces and poke them into surfaces; Fragaszy \& AdamsCurtis, 1991). According to Fragaszy \& Adams-Curtis (1991), the ability of capuchins to produce different forms of manipulation (i.e. generativity) is evident in several dimensions: the variety of actions performed with the same object (e.g. hit, push, pull, tear, insert, handle, rub), the variety of objects to which the same act is directed (e.g. food, movable objects, surfaces, subject's body parts), and the frequency and proportion of relational behaviours (e.g. place an object in relationship to the body, to another object or to a surface). An interesting form of relational behaviour is, for instance, fur rubbing (or anointing), in which an individual applies a substance, most commonly plant material or invertebrates such as ants or millipedes, to its fur using the hands and tail (Fragaszy et al., 2004b). Fur rubbing is hypothesized to be a form of self-medication, and experimental evidence indicates that this behaviour is effective in reducing the parasite diversity and loads in capuchin monkeys (Weldon et al., 2003; Alfaro et al., 2012).

While foraging, capuchin monkeys use their hands to explore the environment in many different ways. For example, wild capuchins probe inside holes and crevices, using their whole hands to feel for water and food sources (Fig. 4; Fragaszy et al., 2004b) or knock nuts into pits on anvil surfaces as a means of detecting when they are in a stable position before cracking them (Sapajus libidinosus; Fragaszy et al., 2013). Although other perceptual systems are sure to be involved, capuchins receive information from at least two different systems, visual and tactile, when they grasp an
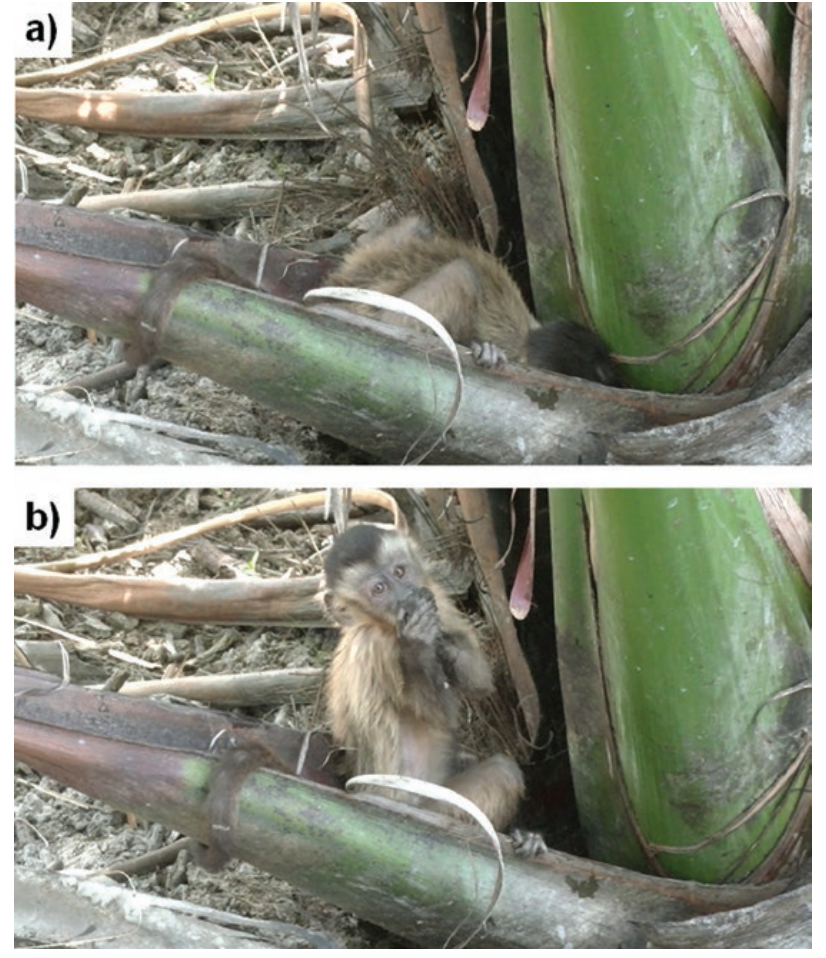

Figure 4. A young capuchin (Sapajus libidinosus) dips its left hand into the water stored at the base of a palm tree (A) and then sucks the water from its hand (B). Photographs by M. J. Fonseca de Oliveira, EthoCebus project.

object. In fact, manual actions are typically guided by the visual system in diurnal primate species. However, studies investigating the integration of information coming from the sensory systems of sight and touch are sparse in nonhuman primates. Blakeslee $\&$ Gunter (1966) demonstrated that capuchins are able to recognize in the tactile modality objects that they have seen in the visual modality and vice versa. Recently, it has also been demonstrated that tactile information can improve visual object discrimination in capuchins (Sapajus spp.; Carducci et al., 2018). In fact, these monkeys learned to recognize objects with different surface structures in fewer trials when they perceived the objects both visually and haptically than when they were prevented from touching them (Carducci et al., 2018). Thus, information from touch influenced perceptual and/or attentional processes in the visual modality. These findings, also demonstrated in kea parrots (Nestor notabilis), suggest possible enhancement effects owing to synergy of the two forms of sensory information and encourage further investigation of how manual exploration affects visual object recognition in species with a high proclivity to handle edible and non-edible items (Carducci et al., 2018). 
Wild bearded capuchins (S. libidinosus) also tap and lift stones in the process of determining which of the two stones is heavier (Visalberghi et al., 2009; Fragaszy et al., 2010). Tap scanning is used as a detection technique that apparently generates acoustic information about the content of cavities or more generally about the density of the material. Wild tufted capuchins tap branches with their fingertips or fingernails while searching for invertebrate prey (Gunst et al., 2010a). Captive tufted capuchins (Sapajus spp.) tap nuts with their fingertips in the course of choosing which ones to open, avoiding empty ones (Visalberghi \& Néel, 2003; Phillips et al., 2004). Moreover, to open a hard-shelled nut efficiently, captive capuchins are able to select an effective tool based on the weight, by lifting the tool itself (Schrauf et al., 2008), and they can choose the hardest substrates to support efficient nut cracking (Pouydebat et al., 2006). Captive capuchins are also able to gather information regarding the pliability of an object either by manipulating the object themselves or by observing a human demonstrator repeatedly bending the object in front of them (Manrique et al., 2011). As mentioned earlier, capuchins frequently reach into crevices and other places where vision is not possible to search for and retrieve food items (Fig. 4). When they cannot fit hands into crevices, they occasionally use tools to probe into and perceive the content (Fragaszy et al., 2004b). The capacity to perceive through the recruitment of inert components is commonly known as extended haptic perception (Burton, 1993). This capacity, although mostly unexplored in capuchins, requires a highly developed haptic sensitivity that allows perception of mechanical and dynamic aspects of the unseen terminal end of the tool.

Lacreuse \& Fragaszy (1997) observed the manual exploratory procedures performed by humans and captive tufted capuchin monkeys reaching through an aperture in an opaque panel to find sunflower seeds deposited on the surface of irregularly shaped clay objects. Interestingly, all the manual exploratory procedures performed by humans were also performed by the capuchins. The percentage of occurrence of the exploratory procedures was shape dependent. For example, for both species, rubbing back and forth on a surface was more frequent for the shapes baited on the top surfaces, whereas inserting one or more fingers into a hole was restricted to shapes with concave places. However, compared with humans, capuchins performed less object contour following and enclosure movements. Moreover, humans performed more exhaustive and longer exploratory procedures than capuchins, which limited their haptic explorations to a very small portion of the shapes, usually the area surrounding the initial hand contact. Affordances of the tasks and anatomophysiological differences related to tactile acuity might have constrained actions performed by the two species, thus leading to the above results.

More recently, Fragaszy and colleagues addressed the question of whether and how capuchins take into account the spatial features of an object when putting it in relationship to a specific surface (Fragaszy et al., 2011; La Cour et al., 2014). The tasks presented consisted of placing stick objects of varying shapes into matching grooves on a flat surface (Fragaszy et al., 2011; La Cour et al., 2014). Capuchins aligned the objects with the matching groove with poor precision, suggesting that they cannot reliably or easily master object placement tasks that require managing two or more allocentric spatial relationships concurrently. Interestingly, capuchins did not show exploratory activities, such as feeling the surface of the tray with their hands, or actions with the sticks above the tray that looked related to alignment. Similar results were obtained with chimpanzees (Fragaszy et al., 2011; La Cour et al., 2014) but not with children (Fragaszy et al., 2015). These results show that using vision to align objects to other objects and managing more than one spatial relationship between an object and a surface are already more elaborated in 2-year-old humans than in capuchins and chimpanzees. The authors argue that these capabilities in visually guided actions distinguish humans from other primates and probably support the great technological progress and other dexterous activities in our species compared with other primates (Fragaszy et al., 2015).

\section{EXTRACTIVE FORAGING}

Fragaszy et al. (2004b) proposed that the explorative tendencies and combinatorial manipulation of capuchins are likely to lead to exploitation of inaccessible or embedded food sources. Sapajus and Cebus species are widely recognized as skilled extractive foragers, accessing embedded foods and bypassing plant and animal defences in the wild by using a variety of manual actions (Fragaszy et al., 2004b). Extractive foraging refers to searching for and handling foods that are difficult to obtain, such as hard-shelled nuts and fruits, embedded invertebrates or other encased food sources that need to be located and extracted from a protective matrix, such as soil, wood, husk or shell, through skilled manipulation (Parker \& Gibson, 1979). As described below, the repertoire of extractive foraging techniques used by capuchins is outstanding among platyrrhines and resembles that used by catarrhines, such as baboons (Papio spp.; Altmann, 1998; Johnson \& Bock, 2004), macaques (Macaca spp.; Wheatley, 1988; Yamakoshi, 2004; Pal et al., 2018) and chimpanzees (Boesch \& Boesch, 1990; Hohmann, 2009). Other plathyrrhines, such as squirrel monkeys 
and Callitrichids, show a more limited extractive foraging repertoire. Common foraging techniques of Saimiri spp. include the following: vigorously rubbing furred caterpillars on branches, their tail or between their hands before consumption to remove irritating hairs; biting or licking prey directly off foliage; removing the head and sometimes the wings of insects before consumption; and processing husked fruits using their canines and hands (Boinski \& Fragaszy, 1989; Stone, 2006). Within Callitrichids, marmosets eat plant exudates, anchoring the upper incisor teeth in the bark and scraping upwards with their specialized lower incisors, and they inspect foliage and holes in branches to detect prey items that are then captured with the hands or the mouth (Garber, 1992; Schiel et al., 2010); in contrast, tamarins feed on gum only opportunistically, and they usually eat patchily distributed fruit and bark surface insects (Garber, 1992; Dietz et al., 1997).

To describe the food processing techniques of capuchins, we will follow the classification by Fragaszy et al. (2004b), which is based on the number of relationships embodied in the actions. According to this classification, the food processing techniques in which the subject acts directly with the body on a surface or an object (i.e. bite, pull, tap, insert the finger into a hole, etc.) and which do not involve relationships embodied in them can be classified as zero-order actions. Activities in which capuchins combine an object with another object or a surface are defined as first-order actions, because they involve one relationship between the objects, and they are also known as combinatorial actions. First-order actions can be either simple or specific. Simple first-order combinations require only that an object be brought into contact with a stationary substrate, whereas specific first-order actions are more complicated in that they require an alignment between the substrate and the object. Finally, activities in which capuchins combine one object with two others (or with another object and a surface) are defined second-order actions, because they involve two relationships among the objects.

Capuchins very frequently perform zero-order actions while exploring or processing objects and food. For example, S. apella in Suriname forage on larvae (Myelobia sp.) hidden inside the internodes of bamboo stalks (Gunst et al., 2008, 2010a). To locate a larva, capuchins use specific detection patterns that involve different senses: sniffing the bamboo stalk with their nose, putting an ear to bamboo stalk, visually scanning the bamboo stalk, touching the bamboo stalk with a hand, probing into a hole, and tap scanning on the bamboo stalk with the fingers of one hand. Once the larva is located, extraction patterns consist of ripping the bamboo stalk apart by repetitive biting and tearing actions with the hands and teeth and extracting the larva with the fingers. Ripping bamboo appears to be a very strenuous action (Gunst et al., 2008; 2010a). Sapajus apella in Suriname also forage on highly nutritious maripa palm fruits (Maximiliana maripa; Gunst et al., 2010b). An ordered sequence of specific actions is used to process the infructescence: (1) visual and manual inspection of the infructescence to clear the way to an unplucked fruit by moving adjacent fruit items further apart to facilitate the grasp on the basal part of one fruit; (2) grasping, pulling and twisting a fruit to remove it from the infructescence; (3) plucking the fruit from the infructescence; (4) peeling the fruit by holding it in one or both hands and stripping the fibrous epicarp with the teeth from the basal cupule to the apex; (5) eating the mesocarp by scraping it off the kernel with the teeth; and (6) discarding the woody endocarp of the fruit (Gunst et al., 2010b).

Capuchins also perform first-order or combinatorial actions (Fragaszy et al., 2004b). These actions are similar to so-called 'object use', that is 'the manipulation and alteration of a detached object relative to a fixed substrate or medium' (Parker \& Gibson, 1977). One example of the use of combinatorial actions by capuchins to access food is fruit-pounding behaviour (Fragaszy et al., 2004b). Broadly, pounding involves an individual hitting an object against a tree branch or rock moving in an upwards and downwards motion with either one or two hands. Pounds are repeated and can be paused to inspect the object. For example, in the case of Luehea candida pod pounding (O'Malley \& Fedigan, 2005), white-faced capuchins (Cebus capucinus) occasionally pause to pick up seeds from the substrate with their fingers or mouth or to pick out seeds from the tip of the pod with their fingers, teeth and tongue. Moreover, while pounding they sometimes use one hand to grasp the pod while the other is held palm up at an angle beside the substrate to catch seeds as they come out.

According to Fragaszy et al. (2004b), first-order actions can be also specific. An example of a specific first-order action is fulcrum use (Panger, 1998). Fulcrum use involves the application of force on an object, with its longer axis perpendicular to the substrate, working against the substrate (which is used as a fulcrum) without moving the object in the process. This type of combinatorial activity is used by C. capucinus in Costa Rica to break open the fruits of Pithecellobium saman to retrieve bruchid beetle larvae (Merobruchus columbinus) that live in many of the fruits (Panger, 1998). While either sitting or standing, capuchins place the fruit perpendicular to the tree branch and apply force downwards on the ends of the fruit (hung over the branch), with one hand on each end of the fruit, until it breaks.

Simple and specific first-order object pounding to obtain food items that are difficult to access has been observed widely in Cebus and Sapajus species. Sapajus 
macrocephalus in Colombia have been observed using one or both hands to open the hard fruits of the Astrocaryum chambira palm by pounding them against the protruding growth node of a bamboo trunk (Izawa \& Mizuno, 1977). In Suriname, S. apella pound hard fruits and seeds from a variety of trees, such as the Brazil nut (Bertholletia excelsa; Boinski et al., 2000). Sapajus lididinosus in Brazil (Sabbatini et al., 2008) and Sapajus cay in Paraguay (Smith, 2017) access the well-protected seeds of Cariniana estrellensis (Fig. 5). They use one or both hands to hold the fruit and to strike the fruit on a hard substrate, such a tree branch. Then, to obtain the seed, capuchins can: (1) hold the fruit in one hand while using the index finger and thumb of the other hand to extract the seed from the hard casing; or (2) hold the fruit with both hands while using the index finger and, occasionally, teeth to extract the seeds one by one from the casing (Smith, 2017). In Costa Rica, C. capucinus pound snails, duck eggs (Dendrocygna autumnalis), clay wasp hives, fruits and seeds from a variety of plants (Panger, 1998; Panger et al., 2002; O'Malley \& Fedigan, 2005).

Rubbing is another combinatorial activity that is widespread in Cebus and Sapajus species. Broadly, this behaviour involves an individual sliding an object forwards and backwards along a tree branch or rock with either one or two hands while in a sitting or crouching position. In Costa Rica, C. capucinus rub caterpillars, snails, duck eggs (D. autumnalis), clay wasp hives, fruits and seeds from a variety of plants (Panger, 1998; Panger et al., 2002; O’Malley \& Fedigan, 2005). They rub the Sloanea terniflora fruit, moving it backwards and forwards across substrate while applying some degree of pressure to remove its unpleasant hairs (O'Malley \& Fedigan, 2005). Sometimes, they use

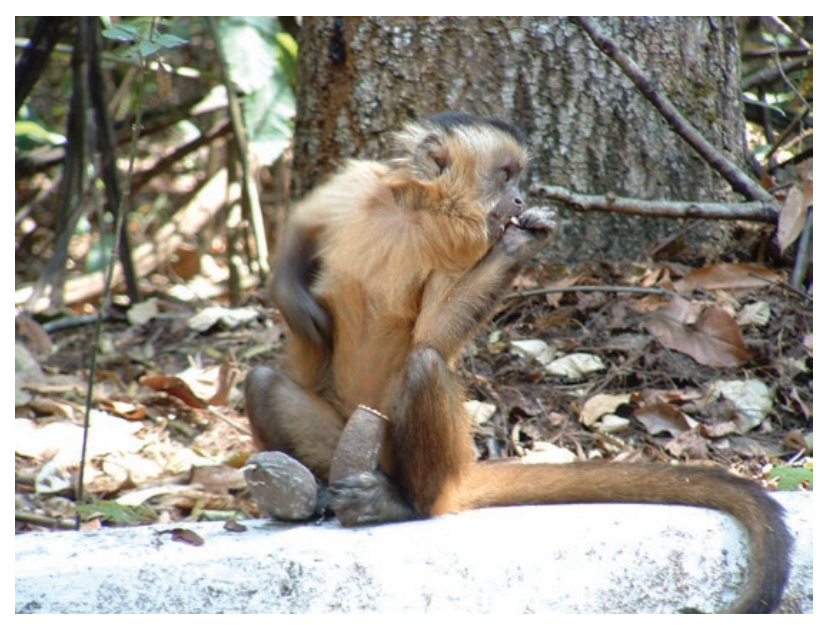

Figure 5. A young female capuchin (Sapajus libidinosus) extracts seeds from the hard fruit of the Cariniana estrellensis. Photograph by G. Sabbatini. a two-handed variation, in which the fruit is rubbed against a substrate with one hand while the other hand brushes or slaps it. According to O'Malley \& Fedigan (2005), this 'rub and brush' variation appears to reflect an effort to keep the Sloanea hairs from flying up into the subject's face.

Sirianni \& Visalberghi (2013) described the two techniques used by $S$. libidinous in Brazil to process cashew (Anacardium sp.) nuts. Typically, when the nut is fresh, capuchins repeatedly rub it on rough surfaces until the shell is partly open and then they extract the kernel with the index finger (Fig. 6). Alternatively, when the
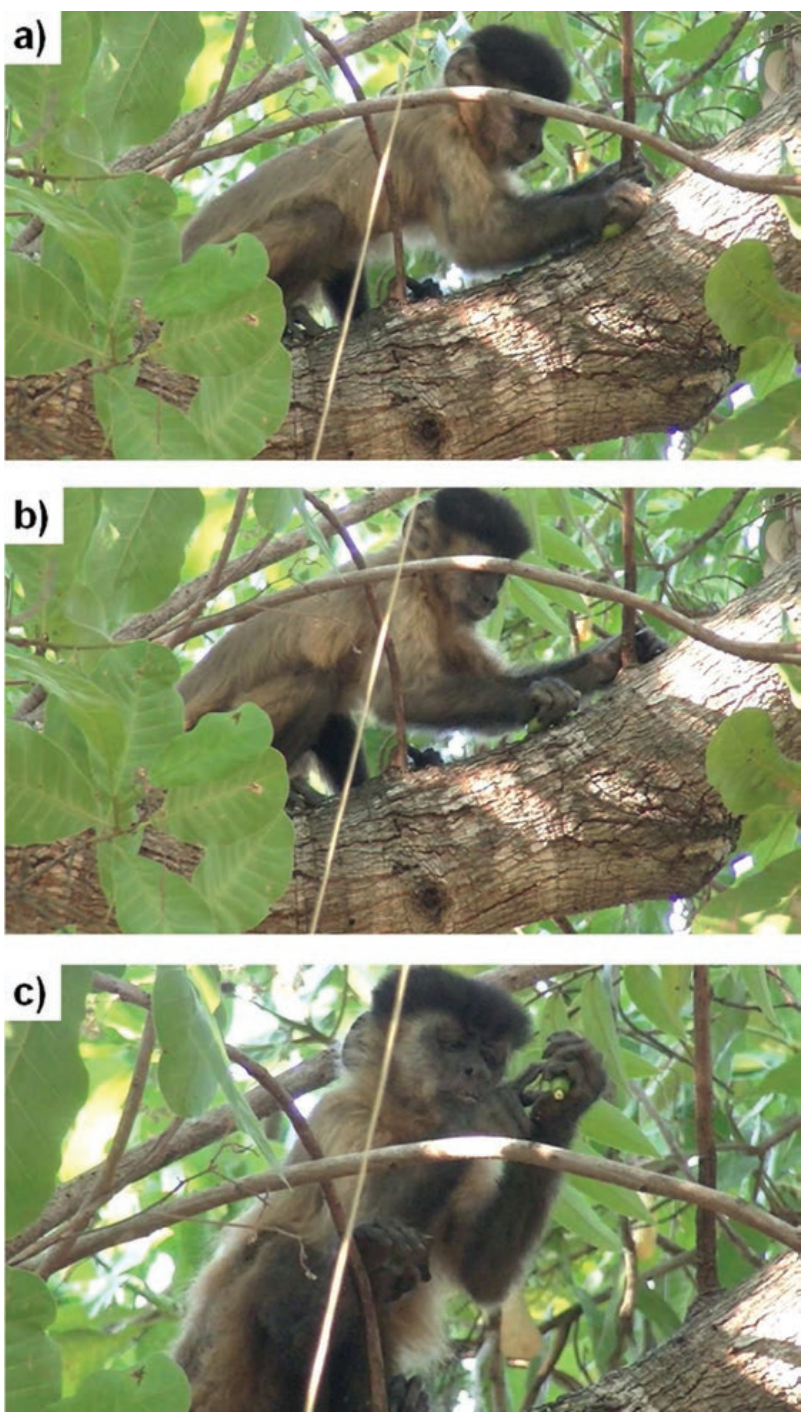

Figure 6. An adult female capuchin (Sapajus libidinosus) rubs a fresh cashew nut pod against the tree bark with her right hand (A, B) and uses her right index finger to extract the kernel from the breached pod (C). Photographs by M. J. Fonseca de Oliveira, EthoCebus project. 
nut is dry, capuchins typically use a stone tool to break the shell and almost never rub the nut. According to Sirianni \& Visalberghi (2013), the use of different techniques for fresh and dry nuts is likely to depend on: (1) higher chances to contaminate the kernel with the caustic liquid when tools smash fresh nuts than when dry nuts are cracked open; and (2) the fact that dry nuts are more resistant than fresh nuts (making rubbing ineffective). The technique used to open the dry nuts is an example of a second-order action, in which one object is combined with two others (Fragaszy et al., 2004b). Moreover, it is an example of tool use, because capuchins pound the dry nuts placed on a hard surface (stone or wood) by using a stone as a percussor (Sirianni \& Visalberghi, 2013). Percussive tool use occurs in a very limited number of mammals, and is seen particularly in tufted capuchins (but see Barrett et al., 2018 for recent findings in untufted capuchins), chimpanzees (Boesch \& Boesch-Achermann, 2000; Matsuzawa, 2011) and macaques (Gumert \& Malaivijitnond, 2013). As we will see below, capuchins are flexible tool users, using many different types of tools to reach a wide variety of goals (Visalberghi et al., 2017).

\section{TOOL USE}

Among New World monkeys, tufted capuchins are the only taxon in which individuals use tools in captive and wild settings (Visalberghi et al., 2017). Operationally, tool use is defined as 'the external employment of an unattached or manipulable attached environmental object to alter more efficiently the form, position, or condition of another object, another organism, or the user itself, when the user holds and directly manipulates the tool during or prior to use and is responsible for the proper and effective orientation of the tool' (Shumaker et al., 2011: 5). More recently, a definition drawn from movement science has been proposed: 'Tool use occurs when an individual moves an external object to produce a force upon another external object or surface, when such movement involves managing altered degrees of freedom (DoF) of movement of its own body' (Fragaszy \& Eshchar, 2017: 318). Adopting this latter point of view, a tool transforms a body-only system into a body-plus-tool system by adding one or more DoF associated with the tool, which may result in a redistribution of the existing DoF of the body (Mangalam \& Fragaszy, 2016). For example, to use a stone held in the hand, a capuchin alters the normal distribution of muscular flexion and extension of the forelimb and the body to accommodate the torque and inertial tensor of the stone. Thus, use of a tool entails adjusting the movements of the body to accommodate the new set of DoF and the altered spatial relationship between the hand and the intended target (which is now contacted by the tool at some distance from the part of body holding the tool). Adopting either of the above definitions influences whether a second-order combination can be considered tool use or not. For example, Panger et al. (2002) described a processing technique, leaf wrap, in which white-fronted capuchins wrap Automeris caterpillars and Sloanea terniflora fruits in leaves before rubbing them against a substrate. Both Automeris caterpillars and Sloanea terniflora fruits have chemical or mechanical defences that can cause pain and/or discomfort when touched. Therefore, the monkeys are most probably using the leaves to protect their hands when rubbing the objects to remove noxious substances. Leafwrapping can be considered tool use according to the definition by Shumaker et al. (2011), but not according to the definition by Mangalam \& Fragaszy (2016), because using a leaf as a glove to protect the hand does not alter the DoF of the hand-only system.

Tool use has its roots in early motor actions and relies on motor actions for its execution (Adolph \& Franchak, 2017). In capuchins, the acquisition of tool use skills is a developmental process that lasts years (Resende et al., 2008). Combinatorial exploration and manipulation of objects and surfaces and the feedback generated by actions produce information that guides subsequent activity and may lead to the acquisition of tool use (Visalberghi \& Fragaszy, 2012). In fact, learning to use tools entails management of the multiple degrees of freedom involved in generating the correct forces, trajectories and orientations that the tool makes with objects and surfaces, and to do this skilfully takes considerable practice (Bril et al., 2010). The acquisition of tool use is also supported by situational and social features that motivate individuals to manipulate the relevant materials in the right place (Eshchar et al., 2016; Fragaszy et al., 2017). From a cognitive point of view, tool use requires capuchins to perceive that a goal is beyond their abilities, recognize that an object can serve as a means to augment their abilities, and execute the necessary movements to use the tool.

In captivity and in the wild, capuchin monkeys use tools to probe, dig or pound mainly to access food sources, and sometimes they modify an object so that it serves, or serves more effectively, as a tool (Shumaker et al., 2011; Visalberghi et al., 2017). Thus, we will focus on the manufacture and use of the following tools: (1) probing tools; (2) digging tools; (3) pounding tools; and (4) complementary tools, with a special emphasis on data collected in the wild.

\section{Probing tools}

Using a stick (or another long, thin, relatively rigid object) to extend reach is one of the most common 
forms of tool use observed in nonhuman primates (Shumaker et al., 2011; Visalberghi et al., 2017). Capuchins extract food with probing sticks both in captivity (e.g. Fragaszy et al., 2004b; Sabbatini et al., 2012) and in the wild (e.g. Mannu \& Ottoni, 2009; Souto et al., 2011). At the Parque Nacional da Serra da Capivara, in Brazil, wild bearded capuchins (S. libidinosus) use sticks either as probing tools to access honey, vertebrate prey, insect nests and water or to poke potentially dangerous animals during threat events (Mannu \& Ottoni, 2009; Falótico \& Ottoni, 2014). Capuchins usually use the probes as follows: (1) to expel prey from their hiding places; (2) to dip for honey, in similar manner to chimpanzees; and (3) to probe in termite nests. A typical probing episode starts with the monkey inspecting the possible nest or hiding place and then going to a near tree to take or make a probe and transport it to the target place (Falótico \& Ottoni, 2014). The production of probe tools frequently involves some modification procedure, such as detaching a branch with the hand(s) and/or mouth, trimming leaves from the distal part of the branch and/or thinning the proximal tip (Mannu \& Ottoni, 2009). The probing behaviour can be performed using the hands or the mouth to push the probe while the monkey is on the ground or on a rock wall (with a bipedal or tripedal posture), or even hanging upside down from a tree trunk (Falótico \& Ottoni, 2014).

Blonde capuchins (Sapajus flavius) living in a fragment of Atlantic Forest (Brazil) were observed collecting termites (Nasutitermes sp.) by using probing sticks (Souto et al., 2011). According to the authors, the behaviour consists of the following three main steps. First, the monkey approaches the nest and taps the nest exterior using both palms (when in front of the nest, the body is in a squatting position, and the tail is used to anchor the body on a stable horizontal branch). Second, the monkey tears off a branchlet (hereafter, stick) from the tree where the nest is located, perforates the nest with it and then inserts it into the nest. The monkey inserts the stick by rotating while pressing its basal portion against the nest and continuously rotates the stick using one hand while perforating the nest. Third, the monkey pulls the stick out of the nest, inspects the stick and eats the termites attached to it. Souto et al. (2011) assessed that tapping had a strong positive influence on the number of termites extracted per insertion, whereas rotating prevented the stick from breaking while inserting it into the nest. According to Souto et al. (2011), when fishing for termites, blonde capuchins express bimanual role differentiation, object modification and sequences of manual actions. All these features are supported by having two hands free.

\section{Digging tools}

Bearded capuchins at the Parque Nacional da Serra da Capivara use stones as digging devices to loosen the soil and unearth underground plant parts or fossorial arthropods (Moura \& Lee, 2004; Mannu \& Ottoni, 2009; Falótico et al., 2017). The monkeys typically use the stones as pestles, holding them with one or both hands and hitting them against the soil. The stones are then dropped, and the capuchins begin digging with one or both hands. Another technique involves hitting the stones against the ground with one hand while removing the loosened soil with the other hand. In some digging episodes, the stones are also used as 'hoes' to draw the dirt out of the hole. The consumption of the underground storage organs after excavation also requires the removal of the external fibrous hard layer, which is usually done with the hands and teeth and, less frequently, using stones to smash the underground storage organs to access the inner part. Other widely used resources are the roots of the louro tree (Ocotea sp.), excavated beside the trunk of the tree (Falótico et al., 2017). Before consuming the root cores, the monkeys peel the roots, usually by rubbing them between the hands or against trunks or rocks. The use of digging tools to harvest underground plant parts is another behaviour that capuchins have in common with chimpanzees (Hernandez-Aguilar et al., 2007).

For capuchins, besides plant parts, the most excavated resources are trapdoor spiders (e.g. Actinopus sp., Magula sp. and unknown species), so called because they build web-coated tunnels and cover the entrance with a camouflaged web cap. While foraging on the ground, monkeys find the web cap, identify the tunnel and initiate the excavation (Falótico et al., 2017).

\section{Pounding tools}

Pounding nuts and other encapsulated food items with a stone on a hard surface requires that two spatial relationships between objects are processed concurrently (Visalberghi \& Fragaszy, 2012). In this situation, the nut must not only be placed in relationship to the hammer, but, at the same time, must also be placed correctly on a hard anvil in order for the pounding to be successful (Fig. 7). Apart from managing more relationships when cracking nuts compared with other tool-using contexts, the individual has to select a hammer and an anvil of appropriate mass and composition for the nut and to bring the elements together before acting (Boesch \& Boesch, 1984; Spagnoletti et al., 2011). Wild tufted capuchin monkeys living in seasonally dry Cerrado and Caatinga habitats in the north-east and centre of Brazil (S. libidinosus, Sapajus xanthosternos and $S$. flavius) use stone hammers as follows: (1) to crack nuts of different species, other 
encapsulated fruits and seeds, and shells of crustaceans and molluscs (Fragaszy et al., 2004a; Moura \& Lee, 2004; Waga et al., 2006; Ottoni \& Izar, 2008; Canale et al., 2009; Ferreira et al., 2010; Cutrim, 2013; Mendes et al., 2015); (2) to process plant parts protected by thorns (Moraes et al., 2014); and (3) to break and/or enlarge holes in tree trunks or rocks and to pulverize pebbles (Falótico \& Ottoni, 2016).

At Fazenda Boa Vista, researchers have carried out field observations and many field experiments to investigate how skilful bearded capuchins (S. libidinosus) are when using stone tools and making decisions concerning tool use (for a detailed review, see Visalberghi \& Fragaszy, 2013; Visalberghi et al., 2017). The monkeys crack several species of palm nuts across the year, exploiting them opportunistically (Spagnoletti et al., 2011). The stones weigh on average $\sim 1 \mathrm{~kg}$, which is a considerable proportion of adult body mass (adult males average $3.6 \mathrm{~kg}$; adult females $2.1 \mathrm{~kg}$; Fragaszy et al., 2016). In fact, to crack palm nuts, stone tools should be resistant and heavy. Heavier stones are more expensive to lift and use but produce more kinetic energy than smaller stones. Adults typically crack a nut open in ten or more strikes, with variability in accord with the mass and skill of the monkey, the mass of the stone tool and the physical properties of the nut (Fragaszy et al., 2010; Spagnoletti et al., 2011).

Westergaard \& Suomi (1997) examined, in captivity, the grips used by capuchin monkeys for nut cracking. They found that capuchins used two different power grips to crack open walnuts with stone tools. In most cases, they used a jaw-chuck grip, in which a capuchin typically held a stone in a downturned palm by flexion of the fingers against an opposed thumb. Involvement of the fourth and fifth digits was greater as the size and shape of the stone increased. The second hand posture was the bimanual jaw-chuck grip, in which a capuchin held stones either with hands side by side or with one hand overlapping the other. It appeared that subjects used the bimanual jaw-chuck grip to increase the force of the stone on the walnut. Compared with capuchins, wild chimpanzees perform a larger variety of hand postures when cracking nuts (Boesch \& Boesch, 1993). They use a stone or wooden hammer in the ground or directly in the tree. They may hold small hammers (300-600 g) with six different power grips when cracking the nuts, and while in the tree they must simultaneously hold the hammer in one hand and the nuts in the other hand or in the mouth (Boesch \& Boesch, 1993).

At Fazenda Boa Vista, after collecting a nut from a palm tree, capuchins carry the nut to an anvil (usually, a boulder with shallow pits on its surface from previous use as an anvil; Visalberghi et al., 2007). If there is no hammerstone at the anvil, the monkeys transport one from nearby, walking bipedally, adopting an erect posture with the stone in the hands, using a bent-hip, bent-knee walking gait (Duarte et al., 2012; Hanna et al., 2015). Once they have placed the nut in a pit on the anvil, standing bipedally, they lift the stone tool to about shoulder height, then hit it vertically onto the nut (Liu et al., 2009; Fig. 7). Capuchins prospectively manage numerous features of the task (Fragaszy \& Eshchar, 2017). First, they select and transport stone tools of appropriate size and material (Visalberghi et al., 2009). When Visalberghi et al. (2009) tested

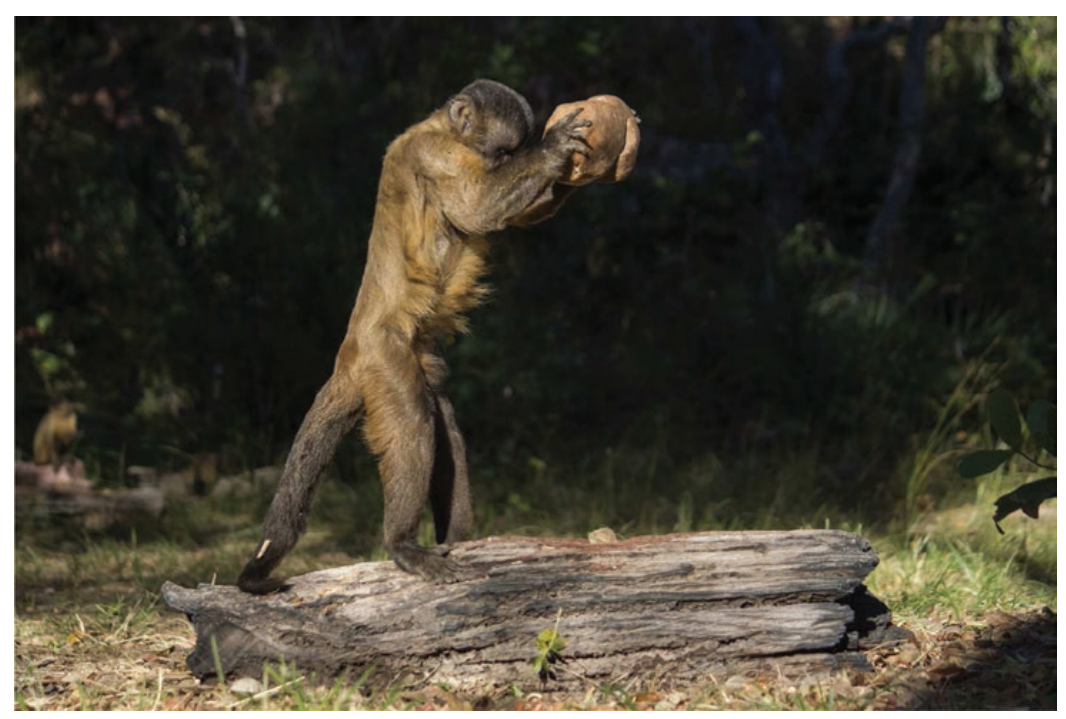

Figure 7. An adult male capuchin (Sapajus libidinosus) uses a stone to open a palm nut placed on a wooden anvil. Photograph by L. A. Marino, EthoCebus project. 
capuchins at Fazenda Boa Vista by providing them with new artificial stones that looked identical, they acquired information about their weight by tapping with fingers on the surface and by using the sound produced to inform their choice. Also, when a tool provided counter-intuitive information, the capuchins relied on the relevant feature (weight) that made the tool functional and disregarded the irrelevant feature (size) (Visalberghi et al., 2009). Moreover, they took the distance to the anvil and the mass of the stone into account when choosing among hammers of different masses in field experiments (Visalberghi et al., 2009; Massaro et al., 2012). Second, monkeys position the nut in the pit(s) of the anvil, rather than on its flat surface, with its more symmetrical edges facing the lateral sides of the pit, so that it is more stable and firm even after a strike (Fragaszy et al., 2013). Third, capuchins modulate the force of their strikes primarily by adjusting the amount of work they add to the stone in the downward strike (Mangalam \& Fragaszy, 2015, 2016; Liu et al., 2016). Moreover, they modulate the force and the other kinematic parameters of their strikes in accord with the physical properties of the nut (Mangalam \& Fragaszy, 2015). They strike the softer nuts with moderate force and modulate the kinematic parameters of each strike on the basis of the condition of the nut, whereas they strike the harder nuts with the maximal force they can generate without modulating the kinematic parameters of each strike until the nut cracks (Mangalam \& Fragaszy, 2015).

\section{Using two distinct complementary tools}

Capuchins, like chimpanzees, are able to use tool sets (i.e. different tools one after the other in the correct functional order) and to use tools in sequence (i.e. use a tool to obtain another tool, which subsequently will serve to obtain an out-of-reach goal; Visalberghi et al., 2017). At the Parque Nacional da Serra da Capivara, bearded capuchins were observed using both tool sets and tools in sequence (Mannu \& Ottoni, 2009; Falótico \& Ottoni, 2014, 2016). In the majority of observations, capuchins pounded a stone to produce or enlarge a hole on a hard surface (trunks or rocks) and then used a stick to probe into the hole to access insect nests or little vertebrates (Mannu \& Ottoni, 2009; Falótico \& Ottoni, 2016). Typically, the monkeys were searching for or chasing prey (e.g. lizards or scorpions) or were accessing carpenter bee (Xylocopa spp.) nests. Also, captive capuchins (Sapajus spp.) use tool sets, such as a stone to crack a nut and then a stick to pry out pieces of nut kernel (Westergaard \& Suomi, 1993). They also spontaneously use a short rigid stick to obtain a longer rigid stick (Anderson \& Henneman, 1994), or a rigid stick to obtain an out-of-reach flexible one that could be used to dip into a baited $90^{\circ}$ angled tube (Sabbatini et al., 2014).

\section{CONCLUSIONS}

In this paper, we have presented a brief critical overview of the current knowledge on object grasping and manipulation in capuchin monkeys. Capuchins represent a taxonomic group of particular interest for the study of primate manual functions. Unlike other platyrrhines, they show remarkable similarities with more dexterous catarrhines. In terms of ontogenetic motor development, capuchins are less precocious than other platyrrhines; however, they can move single digits (especially the thumb) independently, and during growth, they learn how to use their hands effectively to exploit a large variety of embedded foods unavailable to other platyrrhines. Besides manual dexterity, cognitive skills, such as persistence in manipulation and the ability to produce/coordinate different actions, are the key ingredients of their success as extractive foragers and tool users.

Following the idea that cognition is embodied and grounded in the sensorimotor system, we considered the manual functions of capuchins from different perspectives, including anatomofunctional and behavioural findings, and highlighted how much information on their cognitive capabilities may be derived from the study of object grasping and manipulation. We also devoted special attention to describe the contexts in which the skilled manual behaviours of capuchins occur. Overall, the anatomofunctional findings suggest that, during primate evolution, New World capuchin monkeys developed somatosensory areas underpinning complex manual behaviours, which parallel those of Old World primates. Likewise, behavioural findings indicate that capuchins plan grasping actions and manipulate food that must be extracted from resistant matrices in ways that parallel those of catarrhines.

Manual behaviour is an effective means of understanding cognition. In particular, we illustrated how: (1) studying the ontogeny of manipulation in capuchins is crucial to understand how these monkeys interact with the environment and learn; (2) assessing the ability of capuchins to plan and perform grasping offers insight into their ability to anticipate future actions; and (3) evaluating the manipulative behaviours of capuchins during food processing testifies that they have not only a high degree of manual dexterity but also high persistence in goal achievement, sensitivity to the effectiveness and efficiency of their actions and understanding that, in some instances, an object 
can serve as a tool to reach a goal that is beyond their abilities.

We strongly encourage the study of manual behaviours in view of the bodily and environmental context in which they occur. Future studies in the wild will provide new insights into the diversity of hand use in different ecological contexts, whereas studies in captive settings will provide new insights into the diversity of hand use in controlled conditions. Among many aspects related to manual functions, it will be important to clarify the ability of capuchins to carry out the following: (1) to move the fingers in independent ways; (2) to exert force with the fingers on the object during the different grip patterns; (3) to achieve pre-shaping of the fingers during reaching movements; (4) to use hands in coordination with other parts of their body during manipulative behaviours; and (5) to use objects to extend haptic perception. Moreover, kinematics of grasping in capuchins require further attention (see Reghem et al., 2013).

The evolution of manual skills has been accompanied by many related changes of brain architecture in primates. There is still much more to discover concerning the relationship between manual functions and cognition. The study of manual functions is crucial for a number of disciplines, such as anthropology, biology, psychology and, more recently, bio-engineering and robotics. Also, this research will continue to grow in the future thanks to the development of new methods to quantify the ability to grasp and manipulate objects. Research on manual functions in capuchins, and other genera, has the potential to provide important insights into the evolution of primates.

\section{ACKNOWLEDGEMENTS}

This paper is based on a contribution to the European Federation for Primatology symposium, 'What an interdisciplinary approach can tell us about the evolution of grasping and manipulation', held on 21-25 August 2017 at the University of Strasbourg in France and organized by Emmanuelle Pouydebat and Ameline Bardo. The proceedings have been collated into a Special Issue of the Biological Journal of the Linnean Society, guest edited by Emmanuelle Pouydebat and Ameline Bardo. We thank two anonymous reviewers for their thoughtful suggestions and constructive comments on the manuscript. We acknowledge the EthoCebus project for the opportunity to collect images on manual behaviour of wild bearded capuchin monkeys (Sapajus libidinosus) in Piaui, Brazil. Paola Carducci received financial support from EVOzoica Association (research grant 'INCIPIT 2018', grant no. 01/2018).

\section{REFERENCES}

Adams-Curtis LE, Fragaszy DM. 1994. Development of manipulation in capuchin monkeys during the first six months. Developmental Psychobiology 27: 123-136.

Adolph KE, Franchak JM. 2017. The development of motor behavior. Wiley Interdisciplinary Reviews: Cognitive Science 8: $1-2$.

Agostini I, Visalberghi E. 2005. Social influences on the acquisition of sex-typical foraging patterns by juveniles in a group of wild tufted capuchin monkeys (Cebus nigritus). American Journal of Primatology 65: 335-351.

Alfaro JWL, Matthews L, Boyette AH, Macfarlan SJ, Phillips KA, Falótico T, Ottoni E, Verderane M, Izar P, Schulte M, Melin A, Fedigan L, Janson C, Alfaro ME. 2012. Anointing variation across wild capuchin populations: a review of material preferences, bout frequency and anointing sociality in Cebus and Sapajus. American Journal of Primatology 74: 299-314.

Altmann SA. 1998. Foraging for survival: yearling baboons in Africa. Chicago: University of Chicago Press.

Anderson JR, Henneman MC. 1994. Solutions to a tool-use problem in a pair of Cebus apella. Mammalia 58: 351-362.

Ankel-Simons F. 2007. Primate anatomy: an introduction, 3rd edn. Amersterdam: Elsevier Academic Press.

Aversi-Ferreira TA, Diogo R, Potau JM, Bello G, Pastor JF, Aziz MA. 2010. Comparative anatomical study of the forearm extensor muscles of Cebus libidinosus (Rylands et al., 2000; Primates, Cebidae), modern humans, and other primates, with comments on primate evolution, phylogeny, and manipulatory behavior. The Anatomical Record 293: 2056-2070.

Aversi-Ferreira RA, Maior RS, Aziz A, Ziermann JM, Nishijo H, Tomaz C, Tavares MCH, Aversi-Ferreira, TA. 2014. Anatomical analysis of thumb opponency movement in the capuchin monkey (Sapajus sp). PLoS One 9: e87288.

Aversi-Ferreira TA, Maior RS, Carneiro-e-Silva FO, Aversi-Ferreira RA, Tavares MC, Nishijo H, Tomaz C. 2011. Comparative anatomical analyses of the forearm muscles of Cebus libidinosus (Rylands et al. 2000): manipulatory behavior and tool use. PLoS One 6: e22165.

Barrett BJ, Monteza-Moreno CM, Dogandžić T, Zwyns N, Ibañez A, Crofoot MC. 2018. Habitual stone-tool aided extractive foraging in white-faced capuchins, Cebus capucinus. bioRxiv 351619.

Bishop A. 1964. Use of the hand in lower primates. In: Buettner-Janusch J, ed. Evolutionary and genetic biology of primates. New York: Academic Press, 133-225.

Blakeslee P, Gunter R. 1966. Cross-modal transfer of discrimination learning in Cebus monkeys. Behaviour 26: 76-90.

Boesch C, Boesch H. 1984. Mental map in wild chimpanzees: an analysis of hammer transports for nut cracking. Primates 25: $160-170$.

Boesch C, Boesch H. 1990. Tool use and tool making in wild chimpanzees. Folia Primatologica 54: 86-99.

Boesch C, Boesch H. 1993. Different hand postures for pounding nuts with natural hammers by wild chimpanzees. 
In: Preuschoft H, Chivers DJ, eds. Hands of primates. Vienna: Springer, 31-43.

Boesch C, Boesch-Achermann H. 2000. The chimpanzees of the Taï Forest: behavioural ecology and evolution. New York: Oxford University Press.

Boinski S, Fragaszy DM. 1989. The ontogeny of foraging in squirrel monkeys, Saimiri oerstedi. Animal Behaviour 37: 415-428.

Boinski S, Quatrone RP, Swartz H. 2000. Substrate and tool use by brown capuchins in Suriname: ecological contexts and cognitive bases. American Anthropologist 102: 741-761.

Bortoff GA, Strick PL. 1993. Corticospinal terminations in two new-world primates: further evidence that corticomotoneuronal connections provide part of the neural substrate for manual dexterity. Journal of Neuroscience 13: 5105-5118.

Bril B, Rein R, Nonaka T, Wenban-Smith F, Dietrich G. 2010. The role of expertise in tool use: skill differences in functional action adaptations to task constraints. Journal of Experimental Psychology: Human Perception and Performance 36: 825-839.

Burton G. 1993. Non-neural extensions of haptic sensitivity. Ecological Psychology 5: 105-124.

Byrne G, Suomi SJ. 1995. Development of activity patterns, social interactions and exploratory behavior in infant tufted capuchins. American Journal of Primatology 35: 255-270.

Canale GR, Guidorizzi CE, Kierulff MCM, Gatto CAFR. 2009. First record of tool use by wild populations of the yellow-breasted capuchin monkey (Cebus xanthosternos) and new records for the bearded capuchin (Cebus libidinosus). American Journal of Primatology 71: 366-372.

Carducci P, Schwing R, Huber L, Truppa V. 2018. Tactile information improves visual object discrimination in kea, Nestor notabilis, and capuchin monkeys, Sapajus spp. Animal Behaviour 135: 199-207.

Carlson M, Nystrom P. 1994. Tactile discrimination capacity in relation to size and organization of somatic sensory cortex in primates: I. Old-World prosimian, Galago; II. New-World anthropoids, Saimiri and Cebus. Journal of Neuroscience 14: 1516-1541.

Christel MI, Fragaszy DM. 2000. Manual function in Cebus apella. Digital mobility, preshaping, and endurance in repetitive grasping. International Journal of Primatology 21: 697-719.

Cisek P, Kalaska JF. 2010. Interacting with a world full of action choices. Annual Review of Neuroscience 33: 269-298.

Coq JO, Qi H, Collins CE, Kaas JH. 2004. Anatomical and functional organization of somatosensory areas of the lateral fissure of the New World titi monkey (Callicebus moloch). Journal of Comparative Neurology 476: 363-387.

Costello MB, Fragaszy DM. 1988. Prehension in Cebus and Saimiri: I. Grip type and hand preference. American Journal of Primatology 15: 235-245.

Cutrim FHR. 2013. Padrão comportamental e uso de ferramentas em macacos-prego (Sapajus libidinosus) residentes em manguezal. Unpublished doctoral dissertation, Universidade de São Paulo.
Dietz JM, Peres CA, Pinder L. 1997. Foraging ecology and use of space in wild golden lion tamarins (Leontopithecus rosalia). American Journal of Primatology 41: 289-305.

Duarte M, Hanna J, Sanches E, Liu Q, Fragaszy D. 2012. Kinematics of bipedal locomotion while carrying a load in the arms in bearded capuchin monkeys (Sapajus libidinosus). Journal of Human Evolution 63: 851-858.

Dum RP, Strick PL. 2005. Frontal lobe inputs to the digit representations of the motor areas on the lateral surface of the hemisphere. Journal of Neuroscience 25: 1375-1386.

Elias MF. 1977. Relative maturity of cebus and squirrel monkeys at birth and during infancy. Developmental Psychobiology 10: 519-528.

Eshchar Y, Izar P, Visalberghi E, Resende B, Fragaszy D. 2016. When and where to practice: social influences on the development of nut-cracking in bearded capuchins (Sapajus libidinosus). Animal Cognition 19: 605-618.

Falótico T, Ottoni EB. 2014. Sexual bias in probe tool manufacture and use by wild bearded capuchin monkeys. Behavioural Processes 108: 117-122.

Falótico T, Ottoni EB. 2016. The manifold use of pounding stone tools by wild capuchin monkeys of Serra da Capivara National Park, Brazil. Behaviour 153: 421-442.

Falótico T, Siqueira JO, Ottoni EB. 2017. Digging up food: excavation stone tool use by wild capuchin monkeys. Scientific Report 7: 6278.

Fedigan LM. 1990. Vertebrate predation in Cebus capucinus: meat eating in a Neotropical monkey. Folia Primatologica 54: 196-205.

Ferreira RG, Emidio RA, Jerusalinsky L. 2010. Three stones for three seeds: natural occurrence of selective tool use by capuchins (Cebus libidinosus) based on an analysis of the weight of stones found at nutting sites. American Journal of Primatology 72: 270-275.

Fragaszy DM. 1990. Early behavioral development in capuchins (Cebus). Folia Primatologica 54: 119-128.

Fragaszy DM, Adams-Curtis LE. 1991. Generative aspects of manipulation in tufted capuchin monkeys (Cebus apella). Journal of Comparative Psychology 105: 387-397.

Fragaszy DM, Adam-Curtis LE. 1997. Developmental changes in manipulation in tufted capuchins from birth through two years and their relation to foraging and weaning. Journal of Comparative Psychology 111: 201-211.

Fragaszy DM, Adams-Curtis LE, Baer JF, CarlsonLammers R. 1989. Forelimb dimensions and goniometry of the wrist and fingers in tufted capuchin monkeys (Cebus apella): developmental and comparative aspects. American Journal of Primatology 17: 133-146.

Fragaszy DM, Baer JF, Adams-Curtis LE. 1991. Behavioral development and maternal care in tufted capuchins (Cebus apella) and squirrel monkeys (Saimiri sciureus) from birth through seven months. Developmental Psychobiology 24: 375-393.

Fragaszy DM, Crast J. 2016. Functions of the hand in primates. In: Kivel TL, Lemelin P, Richmond BG, Shmitt D, eds. The evolution of the primate hand. New York: Springer, 313-344. 
Fragaszy DM, Eshchar Y. 2017. Tool use in nonhuman primates: natural history, ontogenetic development and social supports for learning. In: Kaas JH, ed. Evolution of nervous systems. Oxford: Academic Press, 317-328.

Fragaszy DM, Eshchar Y, Visalberghi E, Resende B, Laity K, Izar P. 2017. Synchronized practice helps bearded capuchin monkeys learn to extend attention while learning a tradition. Proceedings of the National Academy of Sciences of the United States of America 114: 7798-7805.

Fragaszy DM, Greenberg R, Visalberghi E, Ottoni EB, Izar P, Liu Q. 2010. How wild bearded capuchin monkeys select stones and nuts to minimize the number of strikes per nut cracked. Animal Behaviour 80: 205-214.

Fragaszy DM, Izar P, Liu Q, Eshchar Y, Young LA, Visalberghi E. 2016. Body mass in wild bearded capuchins (Sapajus libidinosus). Ontogeny and sexual dimorphism. American Journal of Primatology 78: 389-484.

Fragaszy D, Izar P, Visalberghi E, Ottoni EB, de Oliveira MG. 2004a. Wild capuchin monkeys (Cebus libidinosus) use anvils and stone pounding tools. American Journal of Primatology 64: 359-366.

Fragaszy DM, Kuroshima H, Stone BW. 2015. "Vision for action" in young children aligning multi-featured objects: development and comparison with nonhuman primates. PloS One 10: e0140033.

Fragaszy DM, Liu Q, Wright BW, Allen A, Brown CW, Visalberghi E. 2013. Wild bearded capuchin monkeys (Sapajus libidinosus) strategically place nuts in a stable position during nut-cracking. PloS One 8: e56182.

Fragaszy DM, Stone BW, Scott NM, Menzel C. 2011. How tufted capuchin monkeys (Cebus apella spp) and common chimpanzees (Pan troglodytes) align objects to surfaces: Insights into spatial reasoning and implications for tool use. American Journal of Primatology 73: 1012-1030.

Fragaszy DM, Visalberghi E, Fedigan L. 2004b. The complete capuchin. Cambridge: Cambridge University Press.

Frey SH, Povinelli DJ. 2012. Comparative investigations of manual action representations: evidence that chimpanzees represent the costs of potential future actions involving tools. Philosophical Transactions of the Royal Society of London B: Biological Sciences 367: 48-58.

Garber PA. 1992. Vertical clinging, small body size, and the evolution of feeding adaptations in the Callitrichinae. American Journal of Physical Anthropology 88: 469-482.

Gibson JJ. 1986. The ecological approach to visual perception. Hillsdale: Erlbaum.

Gumert MD, Malaivijitnond S. 2013. Long-tailed macaques select mass of stone tools according to food type. Philosophical Transactions of the Royal Society B: Biological Sciences 368: 20120413.

Gunst N, Boinski S, Fragaszy DM. 2008. Acquisition of foraging competence in wild brown capuchins (Cebus apella), with special reference to conspecifics' foraging artefacts as an indirect social influence. Behaviour 145: 195-229.

Gunst N, Boinski S, Fragaszy DM. 2010a. Development of skilled detection and extraction of embedded prey by wild brown capuchin monkeys (Cebus apella apella). Journal of Comparative Psychology 124: 194-204.
Gunst N, Leca JB, Boinski S, Fragaszy D. 2010b. The ontogeny of handling hard-to-process food in wild brown capuchins (Cebus apella apella): evidence from foraging on the fruit of Maximiliana maripa. American Journal of Primatology 72: 960-973.

Hamadjida A, Dea M, Deffeyes J, Quessy S, Dancause N. 2016. Parallel cortical networks formed by modular organization of primary motor cortex outputs. Current Biology 26: 1737-1743.

Hanna JB, Schmitt D, Wright K, Eshchar Y, Visalberghi E, Fragaszy D. 2015. Kinetics of bipedal locomotion during load carrying in capuchin monkeys. Journal of Human Evolution 85: 149-156.

Hernandez-Aguilar RA, Moore J, Pickering TR. 2007. Savanna chimpanzees use tools to harvest the underground storage organs of plants. Proceedings of the National Academy of Sciences of the United States of America 104: 19210-19213.

Hill WCO. 1960. Primates, vol. IV, Cebidae, part A. Edinburgh: Edinburgh University Press.

Hoffmann JN, Montag AG, Dominy NJ. 2004. Meissner corpuscles and somatosensory acuity: the prehensile appendages of primates and elephants. The Anatomical Record 281: 1138-1147.

Hohmann G. 2009. The diets of non-human primates: frugivory, food processing, and food sharing. In: Hublin JJ, Richards MP, eds. The evolution of hominin diets. Vertebrate paleobiology and paleoanthropology. Dordrecht: Springer, $1-14$.

Izawa K, Mizuno A. 1977. Palm-fruit cracking behavior of wild black-capped capuchin (Cebus apella). Primates 18: 773-792.

Johnson SE, Bock J. 2004. Trade-offs in skill acquisition and time allocation among juvenile chacma baboons. Human Nature 15: 45-62.

La Cour LT, Stone BW, Hopkins W, Menzel C, Fragaszy DM. 2014. What limits tool use in nonhuman primates? Insights from tufted capuchin monkeys (Sapajus spp.) and chimpanzees (Pan troglodytes) aligning three-dimensional objects to a surface. Animal Cognition 17: 113-125.

Lacreuse A, Fragaszy D. 1997. Manual exploratory procedures and asymmetries for a haptic search task: a comparison between capuchin monkeys (Cebus apella) and humans. Laterality 2: 247-266.

Lemelin P. 2000. Micro-anatomy of the volar skin and interordinal relationships of primates. Journal of Human Evolution 38: 257-267.

Lemelin P, Grafton BW. 1998. Grasping performance in Saguinus midas and the evolution of hand prehensility in primates. In: Strasser E, Fleagle J, Rosenberger A, McHenry $\mathrm{H}$, eds. Primate locomotion: recent advances. New York: Plenum Press, 131-144.

Liu Q, Fragaszy DM, Visalberghi E. 2016. Wild capuchin monkeys spontaneously adjust actions when using hammer stones of different mass to crack nuts of different resistance. American Journal of Physical Anthropology 161: 53-61.

Liu Q, Simpson K, Izar P, Ottoni EB, Visalberghi E, Fragaszy D. 2009. Kinematics and energetics of 
nut-cracking in wild capuchin monkeys (Cebus libidinosus) in Piauí, Brazil. American Journal of Physical Anthropology 138: $210-220$.

Lynch Alfaro JW, De Souza Silva J, Rylands AB. 2012. How different are robust and gracile capuchin monkeys? An argument for the use of Sapajus and Cebus. American Journal of Primatology 74: 273-286.

Macfarlane NB, Graziano MS. 2009. Diversity of grip in Macaca mulatta. Experimental Brain Research 197: 255-268.

Mangalam M, Fragaszy DM. 2015. Wild bearded capuchin monkeys crack nuts dexterously. Current Biology 25: 1334-1339.

Mangalam M, Fragaszy DM. 2016. Transforming the body-only system into the body-plus-tool system. Animal Behaviour 117: 115-122.

Mannu M, Ottoni EB. 2009. The enhanced tool-kit of two groups of wild bearded capuchin monkeys in the Caatinga: tool making, associative use, and secondary tools. American Journal of Primatology 71: 242-251.

Manrique HM, Sabbatini G, Call J, Visalberghi E. 2011. Tool choice on the basis of rigidity in capuchin monkeys. Animal Cognition 14: 775-786.

Martin R. 1990. Primate origins and evolution: a phylogenetic reconstruction. Princeton: Princeton University Press.

Massaro L, Liu Q, Visalberghi E, Fragaszy D. 2012. Wild bearded capuchin (Sapajus libidinosus) select hammer tools on the basis of both stone mass and distance from the anvil. Animal cognition 15: 1065-1074.

Matsuzawa T. 2011. Stone tools for nut-cracking. In: Matsuzawa T, Humle T, Sugiyama Y, eds. The chimpanzees of Bossou and Nimba. Tokyo: Springer, 73-83.

Mendes FDC, Cardoso RM, Ottoni EB, Izar P, Villar DNA, Marquezan RF. 2015. Diversity of nutcracking tool sites used by Sapajus libidinosus in Brazilian Cerrado. American Journal of Primatology 77: 535-546.

Merzenich MM, Kaas JH, Sur M, Lin CS. 1978. Double representation of the body surface within cytoarchitectonic area $3 \mathrm{~b}$ and 1 in "SI" in the owl monkey (Aotus trivirgatus). Journal of Comparative Neurology 181: 41-73.

Moraes BLC, Da Silva Souto A, Schiel N. 2014. Adaptability in stone tool use by wild capuchin monkeys (Sapajus libidinosus). American Journal of Primatology 76: 967-977.

Moura AC, Lee PC. 2004. Capuchin stone tool use in Caatinga dry forest. Science 306: 1909.

Napier JR. 1956. The prehensile movements of the human hand. The Journal of Bone and Joint Surgery. British volume 38: 902-913.

Napier JR. 1960. Studies of the hands of living primates. Journal of Zoology 134: 647-657.

Napier JR. 1961. Prehensibility and opposability in the hands of primates. Symposia of the Zoological Society of London 5: $115-132$.

Napier JR, Napier PH. 1967. A handbook of living primates. London: Academic Press.

Napier JR, Tuttle RH. 1993. Hands. Princeton: Princeton University Press.

O'Malley RC, Fedigan L. 2005. Variability in food-processing behavior among white-faced capuchins (Cebus capucinus) in
Santa Rosa National Park, Costa Rica. American Journal of Physical Anthropology 128: 63-73.

Ottoni EB, Izar P. 2008. Capuchin monkey tool use: overview and implications. Evolutionary Anthropology: Issues, News, and Reviews 17: 171-178.

Padberg J, Disbrow E, Krubitzer L. 2005. The organization and connections of anterior and posterior parietal cortex in titi monkeys: do New World monkeys have an area 2 ? Cerebral Cortex 15: 1938-1963.

Padberg J, Franca JG, Cooke DF, Soares JG, Rosa MG, Fiorani M Jr, Gattass R, Krubitzer L. 2007. Parallel evolution of cortical areas involved in skilled hand use. Journal of Neuroscience 27: 10106-10115.

Pal A, Kumara HN, Mishra PS, Velankar AD, Singh M. 2018. Extractive foraging and tool-aided behaviors in the wild Nicobar long-tailed macaque (Macaca fascicularis umbrosus). Primates 59: 173-183.

Panger MA. 1998. Object-use in free-ranging white-faced capuchins (Cebus capucinus) in Costa Rica. American Journal of Physical Anthropology 106: 311-321.

Panger MA, Perry S, Rose L, Gros-Louis J, Vogel E, Mackinnon KC, Baker M. 2002. Cross-site differences in foraging behavior of white-faced capuchins (Cebus capucinus). American Journal of Physical Anthropology 119: $52-66$.

Parker ST, Gibson KR. 1977. Object manipulation, tool use and sensorimotor intelligence as feeding adaptations in Cebus monkeys and great apes. Journal of Human Evolution 6: $623-641$.

Parker ST, Gibson KR. 1979. A developmental model for the evolution of language and intelligence in early hominids. Behavioral and Brain Sciences 2: 367-381.

Phillips KA, Goodchild LMS, Haas ME, Ulyan MJ, Petro S. 2004. Use of visual, acoustic, and olfactory information during embedded invertebrate foraging in brown capuchins (Cebus apella). Journal of Comparative Psychology 118: 200-205.

Pons TP, Garraghty PE, Cusick CG, Kaas JH. 1985. The somatotopic organization of area 2 in macaque monkeys. Journal of Comparative Neurology 241: 445-466.

Pouydebat E, Gorce P, Bels V, Coppens Y. 2006. Substrate optimization in nut cracking by capuchin monkeys (Cebus apella). American Journal of Primatology 68: 1017-1024.

Pouydebat E, Gorce P, Coppens Y, Bels V. 2009. Biomechanical study of grasping according to the volume of the object: human versus non-human primates. Journal of Biomechanics 42: 266-272.

Reghem E, Chèze L, Coppens Y, Pouydebat E. 2013. Unconstrained 3D-kinematics of prehension in five primates: lemur, capuchin, gorilla, chimpanzee, human. Journal of Human Evolution 65: 303-312.

Resende BD, Ottoni EB, Fragaszy DM. 2008. Ontogeny of manipulative behavior and nutcracking in young tufted capuchin monkeys (Cebus apella): a perception-action perspective. Developmental Science 11: 828-840.

Rilling JK, Insel TR. 1999. The primate neocortex in comparative perspective using magnetic resonance imaging. Journal of Human Evolution 37: 191-223. 
Romanes GJ. 1883. Animal intelligence. New York: D. Appleton.

Rosenbaum DA, Chapman KM, Coelho CJ, Gong L, Studenka BE. 2013. Choosing actions. Frontiers in Psychology 4: 273.

Sabbatini G, Manrique HM, Trapanese C, De Bortoli Vizioli A, Call J, Visalberghi E. 2014. Sequential use of rigid and pliable tools in tufted capuchin monkeys (Sapajus spp.). Animal Behaviour 87: 213-220.

Sabbatini G, Meglio G, Truppa V. 2016. Motor planning in different grasping tasks by capuchin monkeys (Sapajus spp.). Behavioural Brain Research 312: 201-211.

Sabbatini G, Stammati M, Tavares MCH, Visalberghi E. 2008. Behavioural flexibility of a group of capuchin monkeys (Cebus libidinosus) in the National Park of Brasília (Brazil): consequences of cohabitation with visitors. Brazilian Journal of Biology 68: 685-693.

Sabbatini G, Truppa V, Hribar A, Gambetta B, Call J, Visalberghi E. 2012. Understanding the functional properties of tools: chimpanzees (Pan troglodytes) and capuchin monkeys (Cebus apella) attend to tool features differently. Animal Cognition 15: 577-590.

Schiel N, Souto A, Huber L, Bezerra BM. 2010. Hunting strategies in wild common marmosets are prey and age dependent. American Journal of Primatology 72: 1039-1046.

Schrago CG, Russo CA. 2003. Timing the origin of New World monkeys. Molecular Biology and Evolution 20: 1620-1625.

Schrauf C, Huber L, Visalberghi E. 2008. Do capuchin monkeys use weight to select hammer tools? Animal Cognition 11: $413-422$

Shumaker RW, Walkup KR, Beck BB. 2011. Animal tool behavior: the use and manufacture of tools by animals. Baltimore: Johns Hopkins University Press.

Sirianni G, Visalberghi E. 2013. Wild bearded capuchins process cashew nuts without contacting caustic compounds. American Journal of Primatology 75: 387-393.

Smith RL. 2017. Preliminary observations of complex object manipulation in a wild population of Sapajus cay Illiger 1815 (primates: Cebidae) in a fragment of upper Paraná Atlantic Forest, Rancho Laguna Blanca, eastern Paraguay. Acta Ethologica 20: 75-80.

Souto A, Bione CBC, Bastos M, Bezerra BM, Fragaszy D, Schiel N. 2011. Critically endangered blonde capuchins fish for termites and use new techniques to accomplish the task. Biology Letters 7: 532-535.

Spagnoletti N, Visalberghi E, Ottoni E, Izar P, Fragaszy D. 2011. Stone tool use by adult wild bearded capuchin monkeys (Cebus libidinosus): frequency, efficiency and tool selectivity. Journal of Human Evolution 61: 97-107.

Spinozzi G. 1989. Early sensorimotor development in cebus (Cebus apella). In: Antinucci F, ed. Cognitive structure and development in nonhuman primates. Hillsdale: Lawrence Erlbaum Associates, Inc., 55-66.

Spinozzi G, Laganà T, Truppa V. 2007. Hand use by tufted capuchins (Cebus apella) to extract a small food item from a tube: digit movements, hand preference, and performance. American Journal of Primatology 69: 336-352.
Spinozzi G, Truppa V, Laganà T. 2004. Grasping behavior in tufted capuchin monkeys (Cebus apella): grip types and manual laterality for picking up a small food item. American Journal of Physical Anthropology 125: 30-41.

Stone AI. 2006. Foraging ontogeny is not linked to delayed maturation in squirrel monkeys (Saimiri sciureus). Ethology 112: $105-115$

Sur M, Nelson RJ, Kaas J. 1982. Representations of the body surface in cortical areas $3 \mathrm{~b}$ and 1 of squirrel monkeys: comparisons with other primates. Journal of Comparative Neurology 211: 177-192.

Takeshita H, Walraven V. 1996. A comparative study of the variety and complexity of object manipulation in captive chimpanzees (Pan troglodytes) and bonobos (Pan paniscus). Primates 37: 423-441.

Truppa V, Spinozzi G, Laganà T, Piano Mortari E, Sabbatini G. 2016. Versatile grasping ability in power grip actions by tufted capuchin monkeys (Sapajus spp.).American Journal of Physical Anthropology 159: 63-72.

Visalberghi E, Addessi E, Spagnoletti N, Truppa V, Ottoni E, Izar P, Fragaszy D. 2009. Selection of effective stone tools by wild capuchin monkeys. Current Biology 19: 213-217.

Visalberghi E, Fragaszy D. 2012. What is challenging about tool use? The capuchin's perspective. In: Wasserman EA, Zentall TR, eds. Comparative cognition: experimental explorations of animal intelligence. New York: Oxford University Press, 777-799.

Visalberghi E, Fragaszy D. 2013. The EthoCebus Project. Stone tool use by wild capuchin monkeys. In: Sanz C, Call $\mathrm{J}$, Boesch C, eds. Tool use in animals: cognition and ecology. Cambridge: Cambridge University Press, 203-222.

Visalberghi E, Fragaszy D, Ottoni EB, Izar P, Oliveira MG, Andrade FRD. 2007. Characteristics of hammer stones and anvils used by wild bearded capuchin monkeys (Cebus libidinosus) to crack open palm nuts. American Journal of Physical Anthropology 132: 426-444.

Visalberghi E, Néel C. 2003. Tufted capuchins use weight and sound to choose between full and empty nuts. Ecological Psychology 15: 215-228.

Visalberghi E, Sabbatini G, Taylor AH, Hunt GR. 2017. Cognitive insights from tool use in nonhuman animals. In: Call J, ed. APA handbook of comparative psychology. Washington: American Psychological Association, 673-701.

Waga IC, Dacier AK, Pinha PS, Tavares MCH. 2006. Spontaneous tool use by wild capuchin monkeys (Cebus libidinosus) in the cerrado. Folia Primatologica 77: 337-344.

Weldon PJ, Aldrich JR, Klun JA, Oliver JE, Debboun M. 2003. Benzoquinones from millipedes deter mosquitoes and elicit self-anointing in capuchin monkeys (Cebus spp.). Naturwissenschaften 90: 301-304.

Westergaard GC, Suomi SJ. 1993. Use of a tool-set by capuchin monkeys (Cebus apella). Primates 34: 459-462.

Westergaard GC, Suomi SJ. 1997. Capuchin monkey (Cebus apella) grips for the use of stone tools. American Journal of Physical Anthropology 103: 131-135. 
Wheatley BP. 1988. Cultural behavior and extractive foraging in Macaca fascicularis. Current Anthropology 29: 516-519.

Winkelmann RK. 1963. Nerve endings in the skin of primates. In: Buettner-Janusch J, ed. Evolutionary and genetic biology of primates, Vol. 1. New York: Academic Press, 229-259.

Yamakoshi G. 2004. Evolution of complex feeding techniques in primates: is this the origin of great ape intelligence? In: Russon AE, Begun DR, eds. The evolution of thought: evolutionary origins of great ape intelligence. Cambridge: Cambridge University Press, 140-171.

Zander SL, Judge PG. 2015. Brown capuchin monkeys (Sapajus apella) plan their movements on a grasping task. Journal of Comparative Psychology 129: 181-188.

Zander SL, Weiss DJ, Judge PG. 2013. The interface between morphology and action planning: a comparison of two species of New World monkeys. Animal Behaviour 86: 1251-1258. 